\title{
Digital mapping of soil texture in ecoforest polygons in Quebec, Canada
}

\author{
Louis Duchesne ${ }^{\text {Corresp., } 1}$, Rock Ouimet ${ }^{1}$ \\ ${ }^{1}$ Direction de la recherche forestière, Ministère des Forêts, de la Faune et des Parcs, Québec, Québec, Canada \\ Corresponding Author: Louis Duchesne \\ Email address: louis.duchesne@mffp.gouv.qc.ca
}

Texture strongly influences a soil's fundamental functions in forest ecosystems. In response to the growing demand for information on soil properties for environmental modeling, more and more studies have been conducted over the past decade to assess the spatial variability of soil properties on a regional to global scale. These investigations rely on the acquisition and compilation of numerous soil field records and on the development of statistical methods and technology. Here, we used random forest machine learning algorithms to model and map particle size composition in ecoforest polygons for the entire area of managed forests in the province of Quebec, Canada. We compiled archived laboratory analyses of 29,570 mineral soil samples (17,901 sites) and a set of 33 covariates, including 22 variables related to climate, 5 related to soil characteristics, 3 to spatial position or spatial context, 2 to relief and topography, and 1 to vegetation. After 5 repeats of 5-fold cross-validation, results show that models that include 2 functionally independent values regarding particle size composition explain $60 \%, 34 \%$, and $78 \%$ of the variance in sand, silt and clay fractions, respectively, with mean absolute errors ranging from $4.0 \%$ for the clay fraction to $9.5 \%$ for the sand fraction. The most important model variables are those observed in the field and those interpreted from aerial photography regarding soil characteristics, followed by those regarding elevation and climate. Our results compare favorably with those of previous soil texture mapping studies for the same territory, in which particle size composition was modeled mainly from rasterized climatic and topographic covariates. The map we provide should meet the needs of provincial forest managers, as it is compatible with the ecoforest map that constitutes the basis of information for forest management in Quebec, Canada. 
1 Digital mapping of soil texture in ecoforest polygons in Quebec,

Canada

3

4

\author{
Louis Duchesne ${ }^{1 *}$ \\ and \\ Rock Ouimet $^{1}$
}

$6 \quad{ }^{1}$ Direction de la recherche forestière, Ministère des Forêts, de la Faune et des Parcs du Québec, 2700,

7 rue Einstein, Québec (Quebec) G1P 3W8, Canada.

8 *Correspondence: Louis Duchesne, Ministère des Forêts, de la Faune et des Parcs, Direction de la

9 recherche forestière, 2700, rue Einstein, Québec, (Quebec) G1P 3W8, Canada. Email:

10 louis.duchesne@mffp.gouv.qc.ca 


\section{Abstract}

12 Texture strongly influences the soil's fundamental functions in forest ecosystems. In response to 13 the growing demand for information on soil properties for environmental modeling, more and 14 more studies have been conducted over the past decade to assess the spatial variability of soil 15 properties on a regional to global scale. These investigations rely on the acquisition and compilation of numerous soil field records and on the development of statistical methods and technology. Here, we used random forest machine learning algorithms to model and map particle size composition in ecoforest polygons for the entire area of managed forests in the province of Quebec, Canada. We compiled archived laboratory analyses of 29,570 mineral soil samples (17,901 sites) and a set of 33 covariates, including 22 variables related to climate, 5 related to soil characteristics, 3 to spatial position or spatial context, 2 to relief and topography, and 1 to 22 vegetation. After 5 repeats of 5-fold cross-validation, results show that models that include 2 23 functionally independent values regarding particle size composition explain $60 \%, 34 \%$, and $78 \%$ 24 of the variance in sand, silt and clay fractions, respectively, with mean absolute errors ranging 25 from $4.0 \%$ for the clay fraction to $9.5 \%$ for the sand fraction. The most important model 26 variables are those observed in the field and those interpreted from aerial photography regarding 27 soil characteristics, followed by those regarding elevation and climate. Our results compare 28 favorably with those of previous soil texture mapping studies for the same territory, in which 29 particle size composition was modeled mainly from rasterized climatic and topographic covariates. The map we provide should meet the needs of provincial forest managers, as it is compatible with the ecoforest map that constitutes the basis of information for forest management in Quebec, Canada. 


\section{3}

34 Texture strongly influences the soil's fundamental functions in forest ecosystems. In particular, 35 36

\section{Introduction}

the relative content of particles within specific size ranges affects soil mineral weathering rates (Kolka et al., 1996), ion exchange and buffering capacity (Wiklander, 1975), as well as sequestration of nitrogen and carbon (Silver et al., 2000; Telles et al., 2003; Callesen et al., 2007). All these processes influence nutrient pools and cycling in forest ecosystems. Soil texture also affects soil water holding capacity, water uptake by plants and the overall hydrological cycle (Kern, 1995; Hultine et al., 2006; Saxton and Rawls, 2006), as well as the physical stability and supporting functions of soils (Coutts, 1983; Ruel, 1995; Schenk and Jackson, 2005). The importance of soil texture for the functioning of terrestrial and forest ecosystems is highlighted by the fact that it is a key part of various types of models that describe tree growth (Gustafson et al., 2017; D’Orangeville et al., 2018), species distribution (Williams et al., 1996; Itoh et al., 2003), forest disturbances (Schulte et al., 2005; Pourghasemi, 2016), biogeochemistry (Sverdrup and Warfvinge, 1993; Webb et al., 1993), hydrology (Yin and Arp, 1993), and land surface (Verseghy, 2007), among others.

In response to the growing demand for information on soil properties for environmental modeling, more and more studies have been conducted over the past decade to assess the spatial variability of soil properties on a regional to global scale (e.g., Grimm et al., 2008; Hong et al., 2013; Liao et al., 2013; Mansuy et al., 2014; Forkuor et al., 2017; Hengl et al., 2017). These investigations rely on the acquisition and compilation of numerous soil field records and on the development of statistical methods and technology that allow users to compute consistent and reliable spatial predictions of soil properties at various spatial scales (McBratney et al., 2003; Sanchez et al., 2009; Arrouays et al., 2014; Minasny and McBratney, 2016; Malone et al., 2017; Hengl and MacMillan, 2019).

The most advanced soil mapping methods involve producing predictions using optimal statistical models that define statistical relationships between observed soil properties and a set of rasterized environmental covariates that are relevant to explain the distribution of soil properties in the entire area to be mapped (Malone et al., 2017; Hengl and MacMillan, 2019). These covariates generally include information related to climate, vegetation, relief and topography, parent material, geological age, spatial or geographic position, and human or anthropogenic 
63 influences (McBratney et al., 2003; Hengl and MacMillan, 2019). Some of these covariates are 64 typically derived from remote sensing data and digital elevation models, while machine learning 65 algorithms are increasingly used for statistical modeling (Khaledian and Miller, 2020; Wadoux et 66 al., 2020). For example, such an approach has been used to predict various soil properties at a 67 spatial resolution of $250 \mathrm{~m}$ on a global scale (Hengl et al., 2017), for Africa (Hengl et al., 2015), for Argentina (Heuvelink et al., 2020) and for the managed forests of Canada (Mansuy et al., 2014), and at a $5 \mathrm{~m}$ resolution in a $580 \mathrm{~km}^{2}$ agricultural watershed in southwestern Burkina Faso (Forkuor et al., 2017).

Despite their well-demonstrated usefulness for predicting and mapping soil attributes (Viscarra Rossel et al., 2016), remote sensing data also have certain technical limitations (Barnes and Baker, 2000; Bartholomeus et al., 2007; Cécillon et al., 2009; Mulder et al., 2011; Hengl et al., 2017):

1) The covariates derived using remote sensing do not always cover the entire area to be mapped, so missing pixels must be filled using space-filling algorithms.

2) Vegetation, cloud cover, and other adverse weather conditions may hamper the accurate estimation of soil attributes from remote sensing data.

3) All covariates should be rasterized and scaled up or down to the desired resolution for predictions. This process may result in a loss of information in the scaled database.

4) The spectral signature of water surface and anthropogenic infrastructure such as urban areas, roads, buildings, power plants, airports, landfills, mining waste, etc., are not relevant to the mapping of soil properties. Therefore, these areas must be properly masked.

5) Because they only capture the properties of the earth's surface, spectral signatures may be of little interest to map soils that present high vertical variability.

6) Temporal and spatial variation of soil properties such as soil moisture can reduce the accuracy of spectra-based models.

7) In forested areas, the effectiveness of using the forest cover's spectral signature as an indicator of soil properties depends on indirect relationships between soils and vegetation. However, tree phenology, natural and anthropogenic disturbances, and forest dynamics induce spatial and temporal (seasonal to decadal) variations in forest cover. 
93

94

95

96

97

98

99

100

101

102

103

104

105

106

107

108

109

110

111

112

113

114

115

116

117

118

119

120

121 To describe the existing forest resources in detail, the forest attributes of each polygon are also

122 estimated from information compiled from forest inventory programs which are also run

Therefore, they add noise to these relations. Forests are much more dynamic than soils, and short-term changes in forest cover do not necessarily translate into changes in soil properties. This is especially true for the boreal forest, where fire, insect infestations and logging are the main drivers of forest dynamics (Danneyrolles et al., 2019; Duchesne and Ouimet, 2008; Girard et al., 2008).

An alternative method to deriving environmental covariates from remote sensing data is to use field soil information in combination with a traditional (conventional) soil map (Hong et al., 2013; Hengl and MacMillan, 2019). Traditional soil (or ecoforest) maps are typically generated by manually delineating, interpreting, and classifying the shape and color of the surface and vegetation from stereoscopic multispectral aerial photographs in order to form map units with similar characteristics (Soil Science Division Staff, 2017). Soil characteristics are assumed to be relatively homogeneous within polygon boundaries. When available, expert interpretation of the land surface can serve to precisely define soil covariates over various areas of the landscape (Arrouays et al., 2014; Hengl and MacMillan, 2019). Field soil characterization and traditional soil maps are therefore one of the best sources of soil mapping information (Arrouays et al., 2014; Soil Science Division Staff, 2017; Hengl and MacMillan, 2019).

In the province of Quebec, Canada, the ecoforest polygon map constitutes the basis of information for forest management (MFFP, 2020a). Over the past 50 years, the entire territory was analyzed every decade or so from black and white or infrared photographs (scale: $\sim 1: 15,000$ ). Polygons with common characteristics regarding forest attributes (composition, density, age, height), soil parent material, soil drainage, land slope, historical disturbances and ecological type have been delineated and characterized. Water bodies, farmland, unproductive land, roads and other non-forested areas are also delineated. The minimum area for the delimitation varies from 1 to 8 ha, depending on the delimited entity. Photo-interpretation follows standard protocols and is verified using a network of checkpoints that photo-interpreters visit to validate information. The information obtained is then rescaled. Full coverage (approximately up to the $52^{\text {nd }}$ parallel) is publicly available in the form of 1:20,000 ecoforest maps (MFFP, 2020b). 
123 approximately every decade. As part of these surveys, several thousand soil samples have been

124 collected and analyzed over the years to determine their texture. However, these laboratory

125 analyses remain underutilized and, more importantly, they have never served to estimate the

126 spatial variability of soil texture at the scale of ecoforest polygons. Using these precious data, the

127 present analysis aims to map the texture of mineral soil at the scale of the ecoforest polygons in

128 Quebec, Canada. This will allow a more accurate characterization of the spatial variability (2D)

129 of soil texture which is currently roughly classified (fine, medium or coarse texture) based on

130 photo-interpretation of soil characteristics for each ecoforest polygon. We hypothesised that soil

131 particle size composition can be modelled and predicted from a set of environmental covariates,

132 and that the most important model variables would be those observed in the field and those

133 interpreted from aerial photography regarding soil characteristics.

\section{Material and methods}

135 Study area

136 The study area corresponds to the forest area below the current northern limit of the managed

137 forest in the province of Quebec, Canada. It extends up to approximately lat. $52{ }^{\circ} \mathrm{N}$ and covers

138 approximately $583,000 \mathrm{~km}^{2}$, of which $434,667 \mathrm{~km}^{2}$ are classified as productive forests. The

139 normal mean annual temperature (1971-2000) varies approximately from $-2.6{ }^{\circ} \mathrm{C}$ to $7.4{ }^{\circ} \mathrm{C}$, and

140 annual precipitation ranges from $770 \mathrm{~mm}$ to $1,600 \mathrm{~mm}$ (Duchesne et al., 2016). This territory

141 comprises 3 different forest subzones which are mainly associated with variations in the mean

142 annual temperature along the latitudinal gradient (Fig. 1). They are, from south to north: the

143 hardwood forest, the mixed forest, and the continuous boreal forest (MRN, 2013). Based on

144 available knowledge of the physiographic regions of Eastern Canada, 5 soil provinces also

145 characterize the study area (Lamontagne and Nolin, 1997): the St. Lawrence Lowlands, the

146 Appalachians, the Laurentians, the Abitibi and James Bay Lowlands, and the Mistassini

147 Highlands (Fig. 1). They can be distinguished according to parent material, topography, and

148 climate (Lamontagne and Nolin, 1997).

149 Soil sampling and analysis

150 We used soil texture data from 29,570 mineral soil samples (17,901 sites) spread across the

151 entire study area (Fig. 2). The data come from 3 different provincial forest inventory programs. 
152 The first program consists of more than 12,300 permanent sampling plots (PSPs, which are

$153400 \mathrm{~m}^{2}$ circular plots) gradually set up and inventoried by provincial forestry authorities since

1541970 (MFFP, 2016). The PSPs are divided into 5 networks, each with specific objectives (MFFP,

155 2014). The basic network was installed first; it contains the largest number of plots ( $\sim 60 \%$ of the

156 current total). The PSPs of this basic network are distributed randomly over the entire territory,

157 with a sampling intensity of 1 plot per $26 \mathrm{~km}^{2}$ in the hardwood forest, 1 plot per $103 \mathrm{~km}^{2}$ in the

158 mixed forest, and 1 plot per $259 \mathrm{~km}^{2}$ in the continuous boreal forest subzone. From 1989 to

159 1994, this basic network was supplemented by additional PSPs ( 25\%) to increase the precision

160 of forest growth models. The remaining PSPs $(\sim 15 \%)$ are part of 3 networks deployed

161 respectively to monitor the spread of insects and diseases, to obtain information on private

162 forests and to document the effect of silvicultural treatments. Among the many variables

163 recorded in PSPs, the first diagnostic B (thickness $>10 \mathrm{~cm}$ ) and C soil horizons (Soil

164 Classification Working Group, 1998) were sampled for soil texture analysis 1 to $3 \mathrm{~m}$ outside the

165 circular plot, after digging with a shovel and carefully observing the soil profile to select the

166 desired horizons (MFFP, 2016). The relatively thin A horizon, generally characterized by the

167 accumulation of organic matter or the by the eluviation of clay, soil organic matter, iron, or

168 aluminum (Ae), was not sampled. A total of 19,255 soil texture analyses from 10,010 sites across

169 Quebec's managed forests come from the PSP forest inventory program.

170 The second program is a major ecological inventory program that was carried out in Quebec's

171 forests at the end of the last century (MRN, 1994). A total of 28,425 ecological observation plots

172 (EOPs, which are $400 \mathrm{~m}^{2}$ circular plots) were established from 1986 to 2000 to characterize the

173 type of forest cover (composition, structure), understory vegetation (indicator plants) and soil

174 characteristics (e.g., geologic deposit, drainage). Sampling intensity varies depending on the

175 complexity of the terrain and vegetation, with approximately 1 plot per $15 \mathrm{~km}^{2}$ in the hardwood

176 forest, 1 plot per $20 \mathrm{~km}^{2}$ in the mixed forest, and 1 plot per $25 \mathrm{~km}^{2}$ in the continuous boreal

177 forest. The EOPs are distributed along transects that are positioned to cover the types of

178 landform present in each ecological district and to probe specific features. The soil profile was

179 completely characterized and the first diagnostic B and C sol horizons were sampled at a single

180 point located within or near selected plots, with a frequency determined by the regional soil

181 diversity (approximately one third of the EOPs; MRN, 1994). If the $\mathrm{C}$ horizon was absent or

182 unreachable, the sample was taken as deep as possible in the soil profile. If the B horizon was 
183 absent or less than $10 \mathrm{~cm}$ thick, only the C horizon was sampled (MRN, 1994). This inventory

184 program provides soil texture analyses for a total of 9,476 soil horizons $(3,765$ for horizon B and

185 5,711 for horizon C) from 7,085 sites across the managed forests of Quebec.

186 The third set of soil samples comes from the SIP program, a network set up to acquire data on

187 forest productivity of the main ecological types encountered in the province of Quebec. It relies

188 on tree disk sampling and stem analyses for site index determination (MRNF, 2008). At least 5

189 geographically well-distributed site index plots (SIP, circular $400 \mathrm{~m}^{2}$ plots) were established in

190 each of the 4 to 5 major ecological types found in each ecological region. Among the many

191 records measured in each SIP, the first diagnostic B soil horizon (or C horizon if B is not

192 present) was sampled for soil texture determination at a single point within or near the selected

193 plots (MRNF, 2008). The SIP program provides soil texture data for 839 B horizons from

194806 sites. For some unknown reason, 33 sites have 2 samples in the database. The fact that soil

195 texture analyses of these duplicates are coherent for a given site suggests that these sites were

196 sampled twice. Such duplicates in the dataset can also be the result of errors such as wrong

197 attribution of soil samples to sampling locations or data entry errors. In any event, we chose not

198 to arbitrarily discard these observations from the analyses.

199 In the laboratory, soil samples were air dried, crushed, and sieved through a $2 \mathrm{~mm}$ mesh sieve to

200 exclude rock fragments. Particle size composition (sand [2-0.05 mm], silt [0.05-0.002 mm] and

201 clay $[<0.002 \mathrm{~mm}$ ] fractions) was analyzed using the Bouyoucos hydrometer method (Bouyoucos,

202 1962). Samples were analyzed by external accredited laboratories before 2001, then by the

203 organic and inorganic chemistry laboratory of the Direction de la recherche forestière.

204 Covariates

205 We compiled a set of 33 covariates including 22 variables related to climate, 5 related to soil

206 characteristics, 3 to spatial position or spatial context, 2 to relief and topography, and 1 to

207 vegetation (Table 1). To build the model, we selected covariates that had all been measured or

208 observed in sampling plots of the 3 forest inventory programs along with climate data that were

209 estimable for these plots according to their geographic location (see below). For mapping

210 purposes, these covariates also had to have been characterized by photo-interpreters (or

211 estimated for climate data) for all ecoforest map polygons for which we wanted to predict soil

212 texture.

Peer] reviewing PDF | (2021:02:58411:2:0:NEW 31 May 2021) 
213 Climatic data include average annual values (1981-2010) of 22 variables. These covariates were

214 simulated using the stochastic weather generator of the BioSIM software (Régnière et al., 2017).

215 This model provides forecasts based on regional air temperature and precipitation, interpolated

216 from nearby weather stations and adjusted for differences in elevation and location with regional

217 gradients. Climate data were first estimated for each tile of a $0.5^{\prime \prime}(\sim 1 \mathrm{~km})$ resolution raster map,

218 then extracted at the locations of sampling plots and ecoforest polygon centroids. For this, we

219 used the raster package, version 3.0-12 (Hijmans, 2020) in version 3.5.1 of the R software

220 environment (R Core Team, 2019).

221 The soil was characterized using the diagnosed soil horizon (B or C), soil physical environment

222 classes, drainage classes, as well as the origin and depth of soil parent material. We included soil

223 horizon (B or C) as a predictor variable because depth is unknown for PSPs and SIPs samples. In

224 addition, having only 2 sampled depths does not allow the modelling of vertical variability with

225 spline or parametric depth functions (Ma et al. 2021). We hypothesized that soil texture does not

226 exhibit much variability between the $\mathrm{B}$ and $\mathrm{C}$ horizons at a given site, compared to inter-site

227 variability, and focussed primarily on assessing the spatial variability of soil texture. The soil

228 physical environment classes used in Quebec combine information from synthetic soil moisture

229 regime and synthetic soil texture classes (Table 1; MFFP, 2016; MFFP, 2020a). We also

230 characterized relief and topography using altitude and slope classes, and characterized forest

231 cover using a simple 4-class system (deciduous, mixed, conifers, or regeneration). Finally, we

232 captured variability associated with spatial position and context according to the bioclimatic

233 domains, bioclimatic subdomains and ecological regions of the Ecological Land Classification

234 Hierarchy (MFFP, 2020c; MRN, 2013). These spatial entities respectively divide the studied area

235 into 7, 12 and 46 ecological units that represent various combinations of physical environments,

236 climatic regimes, soil provinces, and vegetation. Therefore, these covariates potentially capture

237 some of the spatial variability associated with these environmental characteristics. We included

238 these variables, which reflect the spatial context, to account for the influence of environmental

239 parameters that may have a local or regional influence on soil texture and would not be

240 accounted for by the other covariates (e.g., geologic materials and land surface age since glacial

241 retreat).

242 Statistical analysis and mapping 
243 To ensure consistency between the predictions of sand, silt and clay fractions at each coordinate

244 (which should total 100\%), we first computed the isometric log ratio (ILR) to transform soil

245 texture fractions with the compositions R package, version 1.40-4 (van den Boogaart, 2020), and

246 used the 2 functionally independent values (V1 and V2) for subsequent statistical modeling.

247 Sampling plot data and polygons of the ecoforest map were filtered to exclude agricultural and

248 unproductive forest lands, organic soils (fen, bog), anthropogenic infrastructure, and water

249 surfaces. Therefore, this study considers only productive forest land (defined as having the

250 potential to produce more than $30 \mathrm{~m}^{3}$ of timber per hectare in 120 years or less) characterized by

251 mineral soils.

252 We created dummy variables by converting all categorical variables to as many binary variables

253 as there are categories, using the caret R package, version 6.0-85 (Kuhn, 2020). We then used

254 tree-based random forest machine learning algorithms (method ranger from the caret package) to

255 predict the V1 and V2 orthogonal components of soil texture considering all covariates in the

256 analysis (133 covariates, including the converted dummy variables). To fine-tune the models, we

257 also used the caret package to identify optimal values of the model tuning parameters based on

258 the cross-validation performance. We used 5 repeats of 5-fold cross-validation, and tested a large

259 range of tuning parameter values. The average root-mean-square error was used to select the

260 optimal model using the smallest value. We also tested other machine learning algorithms,

261 including gradient boosting, cubist, and k-nearest neighbors, but with our dataset, the random

262 forest algorithm performed much better than these alternatives.

263 We evaluated the selected models by plotting observed vs. predicted values and comparing slope 264 and intercept regression parameters against the 1:1 line (Piñeiro et al., 2008). We also computed

265 the determination coefficient $\left(\mathrm{R}^{2}\right)$, mean absolute error (MAE) and mean bias error (MBE)

266 statistics using the postResample function of the caret package in the R programming

267 environment (Kuhn, 2020; Willmott and Matsuura, 2005). This function calculates $\mathrm{R}^{2}$ by

268 squaring the correlation between the observed and predicted values. We performed this

269 evaluation on the V1 and V2 orthogonal components of soil texture and on the corresponding

270 compositions (sand, silt and clay fractions) back-transformed from the modeled ILR-transformed

271 values. Finally, we assessed the remaining spatial dependence structure of the model residuals by 
272 computing variograms of the cross-validation residuals using the gstat $\mathrm{R}$ package, version 2.0-4

273 (Pebesma, 2004; Gräler et al., 2016).

274 After this parameterization, we used the models to predict the V1 and V2 orthogonal components

275 of soil texture and the back-transformed particle size composition (sand, silt and clay fractions)

276 for each ecoforest polygon of the provincial forest map. We also estimated the $95 \%$ prediction

277 intervals for V1 and V2 using the quantile regression approach ( $\mathrm{Q}_{.975}-\mathrm{Q}_{.025}$, Meinshausen, 2006;

278 Vaysse et Lagacherie, 2017) using the ranger R package, version 0.12.1 (Wright and Ziegler,

279 2017). In order to reduce computing time, we produced provincial maps in the SIFORT mapping

280 system to translate the conventional ecoforest polygon map (vector or object-oriented images)

281 into a grid of tiles (mixed vector and raster images) separated by 15" ( $375 \mathrm{~m})$ (Pelletier et al.,

282 2007). Each tile's attributes correspond to the information for the polygon at the center of the tile

283 on the conventional ecoforest map. This systematic sampling of the conventional ecoforest

284 polygon map ( 7.7 million polygons) results in a relatively high definition raster map of

285 Quebec's forests ( $\sim 4$ million tiles). In addition, to illustrate the variability of forecasts at finer

286 spatial scales, we produced polygon maps at a chosen location using version 3.4 of QGIS

287 software (QGIS.org, 2020). Particle size composition (sand, silt and clay fractions) was

288 presented on a ternary color scale where the hexadecimal RGB codes from ternary compositions

289 were computed with the tricolore R package, version 1.2.2 (Schöley and Kashnitsky, 2020). We

290 used the dplyr R package, version 0.8.3 (Wickham et al., 2019) for data manipulation as well as

291 the ggplot2 R package, version 3.3.0 (Wickham, 2016) and the cowplot R package, version 1.0.0

292 (Wilke, 2019) for graphic production.

\section{Results}

294 Model performance

295 The observed vs. predicted values of the V1 and V2 orthogonal components of soil texture and 296 the corresponding particle size composition (sand, silt, and clay fractions) are presented in Fig. 3

297 and Fig. 4, respectively. The models explain $46 \%$ and $57 \%$ of the variance $\left(\mathrm{R}^{2}\right)$ for both

298 orthogonal components, with mean absolute errors of 0.39 and 0.41 and mean bias errors of

$299 \pm 0.001$ (Fig. 3). For both models, slope and intercept parameters of the linear regression between

300 observed and predicted values are very close to the 1:1 line. After back transformation, these 
301 models explain $60 \%, 34 \%$, and $78 \%$ of the variance in sand, silt and clay fractions, respectively,

302 with mean absolute errors ranging from $4.0 \%$ for the clay fraction to $9.5 \%$ for the sand fraction,

303 and mean bias errors ranging from $-1.0 \%$ to $1.2 \%$ (Fig. 4 ).

\section{Covariate importance}

305 The measures of relative covariate importance in the V1 and V2 orthogonal component models

306

307

308

309

310

311

312

31

314

315

316

317

318

319

320

321

322

323

324

325

326

327

328

329

are presented in Fig. 5. The most important variables are those observed in the field and interpreted from aerial photography regarding soil characteristics (soil physical environment class and soil parent material, Table 1), followed by those pertaining to elevation and climate, the latter all having comparable importance. Spatial context (Ecological Land Classification Hierarchy), terrain slope, soil horizon (B or C), and forest cover also contribute to the explained variance, but to a lesser degree.

\section{Spatial dependence structure}

Variograms illustrating the spatial dependence structure of the V1 and V2 orthogonal components of particle size composition (sand, silt and clay fractions) and of the model's residuals are shown in Fig. 6. The fact that all 4 variables were found to fit spherical models with a nugget effect denotes spatial structure in the data. Spatial structure was observed over a range of 14.9 to $16.3 \mathrm{~km}$. Spatial dependence between data can be quantified using the nugget-to-sill ratio (NSR, Cambardella et al., 1994; Aidoo et al., 2015). Models captured part of the spatial autocorrelation, as denoted by the greater NSR ratio for residuals than for observations. Nevertheless, a moderate degree of spatial autocorrelation remains in the residuals.

\section{Mapping}

Figure 7 presents the gridded map (15" resolution) of soil particle size composition in ecoforest polygons for the entire area of Quebec's managed forest. At the provincial scale, we visually distinguish the Abitibi and James Bay Lowlands soil provinces in the northwest of the study area. It is characterized by flat topography, with organic deposits in lowland areas in its northwestern part, and mostly fine-textured lacustrine or marine deposits at higher altitudes in its eastern and the southern parts (Blouin and Berger, 2005). The fine-textured mineral deposits originated from the proglacial Ojibway lake in its southern part, and from the prehistoric Tyrell sea that existed during the retreat of the North American ice sheet in its northern part.

Peer) reviewing PDF | (2021:02:58411:2:0:NEW 31 May 2021) 
330 Maps also highlight the medium-textured soils of the Appalachian soil province, located south of

331 the St. Lawrence River. This soil province is characterized by ridges of flattened summits, rocky

332 crests, undulating hills and valleys. The main parent materials are glacial tills on mountaintops

333 and slopes, fluvial deposits along streams, and organic deposits in depressions.

334 Coarser-textured soils are observed in the Laurentians and the Mistassini Highlands soil

335 provinces, both located north of the St. Lawrence River and east of the Abitibi and James Bay

336 Lowlands soil province. The landscape of these two soil provinces consists of ridged rolling

337 hills, crests, and valleys; the main types of parent materials are sandy or gravelly glacial till on

338 hills, sandy or gravelly fluvial deposits in valleys and along water bodies, and organic deposits in

339 depressions.

340 Finally, the map also highlights the coarse-textured soils of the St. Lawrence Lowlands soil

341 province in southern Quebec. Marine deposits in this soil province are from the prehistoric

342 Goldthwait (southern Quebec) and Laflamme (Lac Saint-Jean area) seas. Fine-textured soils

343 predominate at lower altitudes, while coarse-textured soil deposits are more abundant at higher

344 altitudes. However, the mapped forest soils in this soil province are mainly coarse-textured; this

345 can be explained by the fact that fine-textured soils are predominantly farmlands (which were not

346 mapped), and by the much higher density of anthropogenic infrastructure in this region.

347 As examples, we also produced maps illustrating particle size composition of mineral soils in 348 ecoforest polygons at scales of 1:200,000 and 1:100,000, for a region located at the southern

349 edge of the Abitibi and James Bay Lowlands soil provinces, approximately $25 \mathrm{~km}$ south of

350 Lebel-sur-Quévillon (Fig. 8). This region shows a transition from low altitudinal fine-textured

351 and sandy juxtaglacial and lacustrine deposits originating from the prehistoric Lake Ojibway in

352 the west, to medium- and coarse-textured soils in the east, where somewhat thicker till deposits

353 dominate. Organic soils, for which mineral soil texture cannot be estimated, are also abundant in

354 this region.

\section{Mapping accuracy}

356 Evaluation of the $95 \%$ prediction intervals of the V1 and V2 orthogonal components of soil

357 texture reveals that the estimates of the particle size composition are more precise for mineral

358 soils with coarse texture, and less precise for those with fine texture (Fig. 9). This results in 
359 regional differences in mapping accuracy, as estimates of soil texture are less accurate in regions

360 dominated by fine-textured mineral deposits than in regions primarily characterized by coarse-

361 textured mineral deposits. At a finer spatial scale, this also translates into a difference in forecast

362 accuracy between soil physical environment classes and soil parent material types, which were

363 the 2 most important variables in the models.

\section{Discussion}

365

366

367

368

369

370

371

372

373

374

375

376

377

378

379

380

381

382

383

384

385

386

387

\section{Model performance}

From a set of 33 covariates (133, if we include the converted dummy variables), our models respectively explain $60 \%, 34 \%$, and $78 \%$ of the variance $(\mathrm{MAE}=9.6 \%, 7.9 \%, 4.0 \%)$ in sand, silt and clay fractions of 29,093 soil samples distributed throughout the managed forest of the province of Quebec, Canada. By comparison, Hengl et al. (2017) explained $73 \%$ to $79 \%$ of these soil characteristics (MAE $=6.6 \%$ to $9.0 \%$ ) from a set of 158 remote sensing-based soil covariates for more than 600,000 globally distributed soil samples (about 150,000 soil profiles). More precisely, we explained a smaller proportion of the variance in the silt fraction, but we modeled clay fraction with higher precision (smaller error). In contrast, Mansuy et al. (2014) explained only $20 \%, 13 \%$ and $43 \%$ of the variance in sand, silt, and clay fractions of 538 sample plots distributed throughout the Canadian managed forest from a set of 12 topographic and climatic soil covariates. Their forecast was also much less precise than our results and than the global models of Hengl et al. (2017).

A closer look at the SoilGrids map of clay content (https://soilgrids.org/, Hengl et al., 2017) reveals that global predictions completely fail to characterize the fine-textured soils of the Abitibi and James Bay lowlands soil province in Quebec, Canada (Fig. 7), probably due to the very low number of soil samples from this region. Also, as compared to our polygon map, global and Canadian forecasts of soil texture were provided for mineral as well as for organic soils, apparently due to the inability to discriminate organic deposits in the mapping exercise. In addition, despite the higher spatial resolution of the SoilGrids and Canadian maps (250 m), rasterized predictions are somewhat smoothed over the territory. By comparison our polygon map shows much more spatial variability in terms of particle size distribution (Fig. 7-8). The rendering of these abrupt spatial transitions between polygons is made possible by the 
388 characterization and delineation of soils by photo-interpreters. Since photo-interpretation also

389 facilitates the determination of land usage at a relatively fine spatial scale, our polygon map

390 provides forecasts for mineral soils from an entire region in southern Quebec characterized by

391 Mansuy et al. (2014) as agricultural land (and therefore, not mapped), while excluding land with

392 anthropogenic infrastructure.

393 The cross-validation procedure, which involves splitting the original dataset repeatedly into

394 calibration and validation datasets, is commonly used to validate predictive models of soil

395 characteristics, because collecting additional independent samples is often impractical (Hengl

396 and MacMillan, 2019). This procedure does not rely on data that is independent of the original

397 sampling design. Thus, if the sampling is biased or unrepresentative, the validation procedure

398 may not reveal the model's true accuracy. However, if the sampling is unbiased - as we are

399 confident was the case in this study - the randomly selected subsets provide unbiased

400 estimators of the model's true accuracy (Hengl and MacMillan, 2019).

401 Variable importance

402 The most important variables in our soil texture models are soil physical environment classes and 403 soil parent material, followed by altitude and variables regarding climate, which all have a 404 comparable importance (Fig. 5, Table 1). Most important rasterized covariates used for the 405 Canadian soil texture maps by Mansuy et al. (2014) are 4 climate variables (3 variables related to 406 air temperature and 1 to precipitation) and 4 topographic variables (aspect, slope, elevation, and 407 watershed stream). In Hengl et al.'s (2017) global models, the most important covariate to 408 predict soil texture, by far, is depth (up to $2 \mathrm{~m}$ ) below the soil surface. This suggests that a large 409 part of the explained variance of the $\sim 600,000$ soil samples stems from the vertical variability of 410 observations among the $\sim 150,000$ soil profiles. In contrast, our evaluation of model performance 411 and variable importance mainly refers to the spatial variability of soil texture over the studied 412 area. Indeed, we used only 1 or 2 samples per plot (29,570 mineral soil samples from 41317,901 sites) for model parameterization.

414 We hypothesized that soil texture does not vary much between the $\mathrm{B}$ and $\mathrm{C}$ horizons at a given 415 site, compared to inter-site variability. Thus, we focussed primarily on assessing the spatial 416 variability of soil texture. Nevertheless, we included soil horizon (B or C) in the modelling 417 exercise to take into account the variability of soil texture associated with soil horizon and, 
418 indirectly, with sampling depth. Our analyses of each variable's importance revealed that horizon

419 does not rank among the most important variables in our models (Fig. 5). This in itself provides

420 evidence that the vertical variability in soil texture is small compared to spatial variability. In

421 addition, tests for association revealed that the clay fractions of paired soil samples of B and

422 C horizons were closely correlated (Pearson's product moment correlation coefficient of 0.86 ,

$423 \mathrm{t}=183, \mathrm{df}=11996, p$-value $<0.001)$.

424 After depth below the soil surface, the most important variables in global models of soil texture 425 are mean monthly precipitation, mean monthly temperatures, monthly MODIS (Moderate

426 Resolution Imaging Spectrometer) perceptible water vapor images, and digital elevation model-

427 parameters (Hengl et al., 2017). The great importance of climatic variables in global models 428 translates into smoothed forecasts at a local scale. Our results confirm that climate and remote 429 sensing covariates are less relevant for soil texture mapping than the characterization and 430 delineation of soil characteristics by trained photo-interpreters. For example, soil physical 431 environment class 6 (40\% clay on average) and 3 (30\% clay on average) as well as class $2(8 \%$ 432 clay on average) and class 1 (5\% clay on average) are among the most important variables in the 433 models (Table 1, Figure 5). Similarly, fine-textured lacustrine deposits (41\% clay on average), 434 coarse-textured glacial deposits without particular morphology (8\% clay on average) and 435 proglacial deposits (4\% clay on average) are also among the most important discriminating 436 variables of soil texture (Table 1, Figure 5).

\section{Spatial dependence structure}

438 Although our models explain much of the spatial variation in the data, moderate spatial 439 autocorrelations remain in the model residuals. Regionally, spatial interpolation (kriging) of 440 residuals might improve predictions. Hybrid regression-kriging models apparently performed

441 better than individual models for digital mapping of soil organic carbon (Lamichhanea et al. 442 2019). However, combining kriging of residuals with random forest predictions did not always 443 outperform random forest predictions alone (Lamichhanea et al. 2019). As suggested for global 444 soil maps, kriging of residuals would only marginally improve forecasts at the provincial scale, 445 and would come at significant computing cost (Hengl et al., 2017). Combining kriging of 446 residuals with random forest predictions also raises issues related to prediction error propagation. 
447 The accuracy gains that could result from kriging of residuals as well as the methodology to be

448 used for propagation of uncertainty remain to be established.

449 Hengl et al. (2018) proposed another framework for spatial prediction with random forest

450 algorithms, in which buffer distances from sample coordinates are used as explanatory variables

451 to incorporate spatial structure into the modeling process. Regionally, it could also be used to

452 improve predictions; however, it is not adapted for the analysis of large soil sample datasets as

453 the one used in the present study (Hengl et al., 2018).

454 Mapping accuracy

455 The assessment of $95 \%$ prediction intervals allowed us to characterize the spatial distribution of 456 uncertainties associated with the orthogonal components of particle size composition estimated

457 from a set of environmental covariates. The comparison of observed and predicted values

458 (Fig. 4) and the maps of the prediction intervals (Fig. 9) indicate that soils containing more than 459 about $25 \%$ of clay are less frequent, and that their particle size composition (up to $80 \%$ clay) is

460 more difficult to estimate accurately. Thus, models are more imprecise for fine-particle soils

461 characterized by high clay content.

462 Many sources of uncertainty can affect the overall accuracy of mapping, including field

463 sampling, data entry errors, laboratory analysis, characterization of covariates at sampling sites

464 and by photo-interpreters, polygon delineations, climatic covariate estimations, short-range

465 variability, etc. (Hengl and MacMillan, 2019). Our prediction interval maps only refer to the

466 accuracy of the mathematical model; they do not reflect the imprecision of the photo-

467 interpreted covariates, which remains poorly documented. Better quantification of the

468 accuracy of the expert interpretation of land surface and of covariate characterization by

469 photo-interpreters at targeted sites would allow more accurate mapping of the cumulative

470 error associated with soil texture predictions (Kempen et al. 2010). However, this

471 shortcoming only applies when prediction accuracy is evaluated at locations where field data

472 are not available. It does not affect the evaluation of model performance and of prediction

473 uncertainty at sites where covariates have been characterized by field observers.

474 Soil characteristics are known to be difficult to estimate with precision. Our estimates

475 compare favorably to other similar exercises, particularly thanks to the high sampling 
476 intensity, the availability of expert interpretation of the land surface, and the delineation of

477 ecoforest polygons from aerial photography for the entire territory studied. However, the

478 approach used in this study cannot easily be extrapolated to other territories where such

479 information is not available. Also, the propagation of the prediction error associated with $\mathrm{V} 1$ and

480 V2 orthogonal components of soil texture to the back-transformed particle size composition

481 (sand, silt and clay fractions) is a challenge that requires further research.

\section{Conclusion}

483 We used soil texture data from 29,570 mineral soil samples from 17,901 soil profiles to model 484 and map particle size composition in ecoforest polygons of the provincial ecoforest map of 485 Quebec, Canada, using a set of 33 covariates. Our results compare favorably with previous soil 486 texture mapping studies for the same territory, in which soil texture was modeled mainly from 487 rasterized climatic and topographic covariates. Relative measures of variable importance in the 488 models confirm that the characterization and delineation of soil characteristics by trained photo489 interpreters are more relevant for soil texture mapping than climate and remote sensing 490 covariates. Depending on the needs, additional rasterized environmental covariates and methods 491 that incorporate spatial structure into the modeling process could be considered to improve 492 predictions at a local scale. Nevertheless, with mean absolute prediction errors ranging from $4934.0 \%$ for the clay fraction to $9.5 \%$ for the sand fraction, the map we provide should meet the 494 needs of provincial forest managers, as it is compatible with the ecoforest map that constitutes

495 the basis of information for forest management in the province. It could also help refine the 496 contours of soil provinces and subregions, which have only been roughly delineated on a large 497 scale and only as far north as $51^{\circ} \mathrm{N}$, based on available knowledge of the physiographic regions 498 of Eastern Canada.

\section{Acknowledgments}

500 We wish to thank the staff of the Direction des inventaires forestiers of the MFFP, who managed

501 the forest inventory program and supervised all field contractors who carried out soil sampling

502 over the years. We also acknowledge the personnel of the organic and inorganic chemistry

503 laboratory of the Direction de la recherche forestière for performing numerous textural analyses, 504 Marie-Claude Lambert who generated meteorological data, Jean Noël for assistance in spatial 
505 data processing and Denise Tousignant for English editing. We are also grateful to the editor and 506 the three anonymous reviewers for their valuable comments and suggestions to improve the 507 quality of the paper. 
508

509

510

511

512

513

514

515

516

517

518

519

520

521

522

523

524

525

526

527

528

529

530

531

532

533

534

535

\section{References}

Aidoo, E.N., Mueller, U., Goovaerts, P., Hyndes, G.A., 2015. Evaluation of geostatistical estimators and their applicability to characterise the spatial patterns of recreational fishing catch rates. Fish. Res. 168, 20-32. https://doi.org/10.1016/j.fishres.2015.03.013

Arrouays, D., Grundy, M.G., Hartemink, A.E., Hempel, J.W., Heuvelink, G.B.M., Hong, S.Y., Lagacherie, P., Lelyk, G., McBratney, A.B., McKenzie, N.J., Mendonca-Santos, M. d. L., Minasny, B., Montanarella, L., Odeh, I.O.A., Sanchez, P.A., Thompson, J.A., Zhang, G.L., 2014. GlobalSoilMap. Toward a Fine-Resolution Global Grid of Soil Properties. Adv. Agron. 125, 93-134. https://doi.org/10.1016/B978-0-12-800137-0.00003-0

Barnes, E.M., Baker, M.G., 2000. Multispectral data for mapping soil texture: Possibilities and limitations. Appl. Eng. Agric. 16, 731-741.

Bartholomeus, H., Epema, G., Schaepman, M., 2007. Determining iron content in Mediterranean soils in partly vegetated areas, using spectral reflectance and imaging spectroscopy. Int. J. Appl. Earth Obs. Geoinf. 9, 194-203. https://doi.org/10.1016/j.jag.2006.09.001

Blouin, J., Berger, J.-P., 2005. Guide de reconnaissance des types écologiques de la région écologique $6 \mathrm{a}$ - Plaine du lac Matagami et $6 \mathrm{~b}$ - Plaine de la baie de Rupert, ministère des Ressources naturelles et de la Faune, Direction des inventaires forestiers [WWW Document]. URL https://mffp.gouv.qc.ca/publications/forets/connaissances/guideecologique-6ab.pdf

Bouyoucos, G.J., 1962. Hydrometer method improved for making particle size analyses of soils. Agron. J. 54, 464-465. https://doi.org/10.2134/agronj1962.00021962005400050028x

Callesen, I., Raulund-Rasmussen, K., Westman, C.J., Tau-Strand, L., 2007. Nitrogen pools and $\mathrm{C}: \mathrm{N}$ ratios in well-drained Nordic forest soils related to climate and soil texture. Boreal Environ. Res. 12, 681-692.

Cambardella, C.A., Moorman, T.B., Novak, J.M., Parkin, T.B., Karlen, D.L., Turco, R.F., Konopka, A.E., 1994. Field-Scale Variability of Soil Properties in Central Iowa Soils. Soil Sci. Soc. Am. J. 58, 1501-1511. https://doi.org/10.2136/sssaj1994.03615995005800050033x 
536 Cécillon, L., Barthès, B.G., Gomez, C., Ertlen, D., Genot, V., Hedde, M., Stevens, A., Brun, J.J.,

537

538

539

540

541

542

543

544

545

546

547

548

549

550

551

552

553

554

555

556

557

558

559

560

561

562

563 2009. Assessment and monitoring of soil quality using near-infrared reflectance spectroscopy (NIRS). Eur. J. Soil Sci. 60, 770-784. https://doi.org/10.1111/j.13652389.2009.01178.x

Coutts, M.P., 1983. Root architecture and tree stability. Plant Soil 71, 171-188. https://doi.org/10.1007/BF02182653

D’Orangeville, L., Houle, D., Duchesne, L., Phillips, R.P., Bergeron, Y., Kneeshaw, D., 2018. Beneficial effects of climate warming on boreal tree growth may be transitory. Nat. Commun. 9, 1-10. https://doi.org/10.1038/s41467-018-05705-4

Danneyrolles, V., Dupuis, S., Fortin, G., Leroyer, M., de Römer, A., Terrail, R., Vellend, M., Boucher, Y., Laflamme, J., Bergeron, Y., Arseneault, D., 2019. Stronger influence of anthropogenic disturbance than climate change on century-scale compositional changes in northern forests. Nat. Commun. 10, 1-7. https://doi.org/10.1038/s41467-019-09265-z

Duchesne, L., Houle, D., Ouimet, R., Lambert, M.-C., Logan, T., 2016. Aboveground carbon in Quebec forests: stock quantification at the provincial scale and assessment of temperature, precipitation and edaphic properties effects on the potential stand-level stocking. PeerJ 4, e1767. https://doi.org/10.7717/peerj.1767

Duchesne, L., Ouimet, R., 2008. Population dynamics of tree species in southern Quebec, Canada: 1970-2005. For. Ecol. Manage. 255, 3001-3012. https://doi.org/10.1016/j.foreco.2008.02.008

Forkuor, G., Hounkpatin, O.K.L., Welp, G., Thiel, M., 2017. High resolution mapping of soil properties using Remote Sensing variables in south-western Burkina Faso: A comparison of machine learning and multiple linear regression models. PLoS One 12, 1-21. https://doi.org/10.1371/journal.pone.0170478

Girard, F., Payette, S., Gagnon, R., 2008. Rapid expansion of lichen woodlands within the closed-crown boreal forest zone over the last 50 years caused by stand disturbances in eastern Canada. J. Biogeogr. 35, 529-537. https://doi.org/10.1111/j.13652699.2007.01816.x 
564 Gräler, B., Pebesma, E., Heuvelink, G., 2016. Spatio-Temporal Interpolation using gstat. R J. 8,

565

566

567

568

569

570

571

572

573

574

575

576

577

578

579

580

581

582

583

584

585

586

587

588

589

590 204. https://doi.org/10.32614/RJ-2016-014

Grimm, R., Behrens, T., Märker, M., Elsenbeer, H., 2008. Soil organic carbon concentrations and stocks on Barro Colorado Island-Digital soil mapping using Random Forests analysis. Geoderma 146, 102-113. https://doi.org/10.1016/j.geoderma.2008.05.008

Gustafson, E.J., Miranda, B.R., De Bruijn, A.M.G., Sturtevant, B.R., Kubiske, M.E., 2017. Do rising temperatures always increase forest productivity? Interacting effects of temperature, precipitation, cloudiness and soil texture on tree species growth and competition. Environ. Model. Softw. 97, 171-183. https://doi.org/10.1016/j.envsoft.2017.08.001

Hengl, T., De Jesus, J.M., Heuvelink, G.B.M., Gonzalez, M.R., Kilibarda, M., Blagotić, A., Shangguan, W., Wright, M.N., Geng, X., Bauer-Marschallinger, B., Guevara, M.A., Vargas, R., MacMillan, R.A., Batjes, N.H., Leenaars, J.G.B., Ribeiro, E., Wheeler, I., Mantel, S., Kempen, B., 2017. SoilGrids250m: Global gridded soil information based on machine learning. PLoS One 12, 1-40. https://doi.org/10.1371/journal.pone.0169748

Hengl, T., Heuvelink, G.B.M., Kempen, B., Leenaars, J.G.B., Walsh, M.G., Shepherd, K.D., Sila, A., MacMillan, R.A., De Jesus, J.M., Tamene, L., Tondoh, J.E., 2015. Mapping soil properties of Africa at $250 \mathrm{~m}$ resolution: Random forests significantly improve current predictions. PLoS One 10, 1-26. https://doi.org/10.1371/journal.pone.0125814

Hengl, T., MacMillan, R.A., 2019. Predictive Soil Mapping with R. OpenGeoHub foundation, Wageningen, the Netherlands, 370 pages, www.soilmapper.org, ISBN: 978-0-359-30635-0.

Hengl, T., Nussbaum, M., Wright, M.N., Heuvelink, G.B.M., Gräler, B., 2018. Random forest as a generic framework for predictive modeling of spatial and spatio-temporal variables. PeerJ 2018. https://doi.org/10.7717/peerj.5518

Heuvelink, G.B.M., Angelini, M.E., Poggio, L., Bai, Z., Batjes, N.H., van den Bosch, R., Bossio, D., Estella, S., Lehmann, J., Olmedo, G.F., Sanderman, J., 2020. Machine learning in space and time for modelling soil organic carbon change. Eur. J. Soil Sci. 1-17. https://doi.org/10.1111/ejss.12998 
591 Hijmans, R.J., 2020. raster: Geographic Data Analysis and Modeling. R package version 3.0-12 592 [WWW Document]. URL https://cran.r-project.org/package=raster

593 Hong, S.Y., Minasny, B., Han, K.H., Kim, Y., Lee, K., 2013. Predicting and mapping soil 594 available water capacity in Korea. PeerJ 2013, 1-20. https://doi.org/10.7717/peerj.71

595

596

Hultine, K.R., Koepke, D.F., Pockman, W.T., Fravolini, A., Sperry, J.S., Williams, D.G., 2006. Influence of soil texture on hydraulic properties and water relations of a dominant warmdesert phreatophyte. Tree Physiol. 26, 313-323. https://doi.org/10.1093/treephys/26.3.313

Itoh, A., Yamakura, T., Ohkubo, T., Kanzaki, M., Palmiotto, P.A., LaFrankie, J. V., Ashton, P.S., Lee, H.S., 2003. Importance of topography and soil texture in the spatial distribution of two sympatric dipterocarp trees in a Bornean rainforest. Ecol. Res. 18, 307-320. https://doi.org/10.1046/j.1440-1703.2003.00556.x

Kempen, B., Heuvelink, G.B.M., Brus, D.J., Stoorvogel, J.J., 2010. Pedometric mapping of soil organic matter using a soil map with quantified uncertainty. Eur. J. Soil Sci. 61, 333-347. https://doi.org/10.1111/j.1365-2389.2010.01232.x

Kern, J.S., 1995. Geographic Patterns of Soil Water-Holding Capacity in the Contiguous United States. Soil Sci. Soc. Am. J. 59, 1126-1133. https://doi.org/10.2136/sssaj1995.03615995005900040026x

Khaledian, Y., Miller, B.A., 2020. Selecting appropriate machine learning methods for digital soil mapping. Appl. Math. Model. 81: 401-418. https://doi.org/10.1016/j.apm.2019.12.016

Kolka, R.K., Grigal, D.F., Nater, E.A., 1996. Forest soil mineral weathering rates: Use of multiple approaches. Geoderma 73, 1-21. https://doi.org/10.1016/0016-7061(96)00037-7

Kuhn, M., 2020. caret: Classification and Regression Training. R package version 6.0-85 [WWW Document]. URL https://cran.r-project.org/package=caret

Lamichhanea, S., Kumara, L., Wilsona, B., 2019. Digital soil mapping algorithms and covariates for soil organic carbon mapping and their implications: A review. Geoderma 352, 395-413. https://doi.org/10.1016/j.geoderma.2019.05.031 
617 Lamontagne, L., Nolin, M.C., 1997. Cadre pédologique de référence pour la corrélation des sols. 618 Bulletin d'extension numéro 7 du Centre de recherche et de développement sur les sols et 619 les grandes cultures et contribution 971123 du Centre de recherche de l'Est sur les céréales 620 et les oléagineux. Agriculture et agroalimentaire Canada.

621 Liao, K., Xu, S., Wu, J., Zhu, Q., 2013. Spatial estimation of surface soil texture using remote 622 sensing data. Soil Sci. Plant Nutr. 59, 488-500.

623 https://doi.org/10.1080/00380768.2013.802643

624 Ma, Y., Minasny, B., McBratney, A., Poggio, L., Fajardo, M,. 2021. Predicting soil properties in 625 3D: Should depth be a covariate? Geoderma 383: 114794.

626 https://doi.org/10.1016/j.geoderma.2020.114794

627 Malone, B.P., Minasny, B., McBratney, A.B., 2017. Using R for Digital Soil Mapping, Progress 628 in Soil Science. Springer International Publishing. https://doi.org/10.1007/978-3-319$629 \quad 44327-0$

630 Mansuy, N., Thiffault, E., Paré, D., Bernier, P., Guindon, L., Villemaire, P., Poirier, V., 631 Beaudoin, A., 2014. Digital mapping of soil properties in Canadian managed forests at 250 $632 \mathrm{~m}$ of resolution using the k-nearest neighbor method. Geoderma 235-236, 59-73. 633 https://doi.org/10.1016/j.geoderma.2014.06.032

634 McBratney, A.B., Mendonça Santos, M.L., Minasny, B., 2003. On digital soil mapping. 635 Geoderma 117, 3-52. https://doi.org/10.1016/S0016-7061(03)00223-4

636 Meinshausen, N., 2006. Quantile regression forests. J. Mach. Learn. Res. 7, 983-999.

637 MFFP, 2014. Réseaux des placettes-échantillons permanentes du Québec méridional.

638 Gouvernement du Québec, Ministère des Forêts, de la Faune et des Parcs, Direction des 639 inventaires forestiers [WWW Document]. URL

640 https://mffp.gouv.qc.ca/publications/forets/connaissances/Reseaux-PEP.pdf

641 MFFP, 2016. Norme d'inventaire écoforestier, placettes-échantillons permanentes, édition 2016.

642 Gouvernement du Québec, Ministère des Forêts, de la Faune et des Parcs, Direction des 643 inventaires forestiers [WWW Document]. URL

644 https://mffp.gouv.qc.ca/publications/forets/connaissances/Norme-PEP.pdf 
645 MFFP, 2020a. Cartographie du 5e inventaire écoforestier du Québec méridional — Méthodes et 646 données associées. [WWW Document]. URL

647 http://www.mffp.gouv.qc.ca/forets/inventaire/publications-inventaire-forestier.jsp (accessed $648 \quad 11.18 .20)$.

649 MFFP, 2020b. Carte écoforestière avec perturbations. Gouvernement du Québec, Ministère des 650 Forêts, de la Faune et des Parcs [WWW Document]. URL

651 https://www.donneesquebec.ca/recherche/fr/dataset/carte-ecoforestiere-avec-perturbations

652 MFFP, 2020c. Classification écologique du territoire québécois. Gouvernement du Québec, 653 Ministère des Forêts, de la Faune et des Parcs [WWW Document]. URL https://www.donneesquebec.ca/recherche/fr/dataset/systeme-hierarchique-de-classificationecologique-du-territoire

656

657

658

659

660

661

662

663

664

665

666

667

668

669

670

671

672

Minasny, B., McBratney, A.B., 2016. Digital soil mapping: A brief history and some lessons. Geoderma 264, 301-311. https://doi.org/10.1016/j.geoderma.2015.07.017

MRN. 1994. Le point d'observation écologique. Gouvernement du Québec, Ministère des Ressources Naturelles [WWW Document]. URL https://mffp.gouv.qc.ca/publications/forets/connaissances/le-point-observation-ecologiquenormes-tech-34.pdf

MRN, 2013. Cartographie numérique des niveaux supérieurs du Système hiérarchique de classification écologique et banque de données descriptives des districts écologiques.

Gouvernement du Québec, Ministère des Ressources naturelles, Direction des inventaires forestie [WWW Document]. URL https://mffp.gouv.qc.ca/forets/inventaire/pdf/systemereference.pdf

MRNF, 2008. Normes d'inventaire forestier — Analyse des tiges — Sélection, récolte et mesure en laboratoire. Gouvernement du Québec, Ministère des Ressources naturelles et de la Faune, Direction des inventaires forestiers.

Mulder, V.L., de Bruin, S., Schaepman, M.E., Mayr, T.R., 2011. The use of remote sensing in soil and terrain mapping - A review. Geoderma 162, 1-19. https://doi.org/10.1016/j.geoderma.2010.12.018 
673 Pebesma, E.J., 2004. Multivariable geostatistics in S: The gstat package. Comput. Geosci. 30, 683-691. https://doi.org/10.1016/j.cageo.2004.03.012

675

676

677

678

679

680

681

682

683

684

685

686

687

688

689

690

691

692

693

694

695

696

697

698

Pelletier, G., Dumont, Y., Bédard, M., 2007. SIFORT — Système d'Information FORestière par Tesselle, Manuel de l'usager. Gouvernement du Québec, Ministère des Ressources naturelles et de la Faune [WWW Document]. URL http://www.mffp.gouv.qc.ca/publications/forets/fimaq/usager.pdf

Piñeiro, G., Perelman, S., Guerschman, J.P., Paruelo, J.M., 2008. How to evaluate models: Observed vs. predicted or predicted vs. observed? Ecol. Modell. 216, 316-322. https://doi.org/10.1016/j.ecolmodel.2008.05.006

Pourghasemi, H.R., 2016. GIS-based forest fire susceptibility mapping in Iran: a comparison between evidential belief function and binary logistic regression models. Scand. J. For. Res. 31, 80-98. https://doi.org/10.1080/02827581.2015.1052750

QGIS.org, 2020. QGIS Geographic Information System. Open Source Geospatial Foundation Project [WWW Document]. URL http://qgis.org

R Core Team, 2019. R: A language and environment for statistical computing. R Foundation for Statistical Computing. Vienna, Austria [WWW Document]. URL https://www.r-project.org/

Régnière, J., Saint-Amant, R., Béchard, A., Moutaoufik, A., 2017. BioSIM 11 User's Manual. Update of Information Report LAU-X-137. Natural Resources Canada, Canadian Forest Service, Laurentian Forestry Centre.

Ruel, J.-C., 1995. Understanding windthrow: Silvicultural implications. For. Chron. 71, 434445. https://doi.org/10.5558/tfc71434-4

Sanchez, P.A., Ahamed, S., Carré, F., Hartemink, A.E., Hempel, J., Huising, J., Lagacherie, P., McBratney, A.B., McKenzie, N.J., De Lourdes Mendonça-Santos, M., Minasny, B., Montanarella, L., Okoth, P., Palm, C.A., Sachs, J.D., Shepherd, K.D., Vågen, T.G., Vanlauwe, B., Walsh, M.G., Winowiecki, L.A., Zhang, G.L., 2009. Digital soil map of the world. Science (80-. ). 325, 680-681. https://doi.org/10.1126/science.1175084 
699 Saxton, K.E., Rawls, W.J., 2006. Soil Water Characteristic Estimates by Texture and Organic

700

701

702

703

704

705

706

707

708

709

710

711

712

713

714

715

716

717

718

719

720

721

722

723

724

725 Matter for Hydrologic Solutions. Soil Sci. Soc. Am. J. 70, 1569-1578. https://doi.org/10.2136/sssaj2005.0117

Schenk, H.J., Jackson, R.B., 2005. Mapping the global distribution of deep roots in relation to climate and soil characteristics. Geoderma 126, 129-140. https://doi.org/10.1016/j.geoderma.2004.11.018

Schöley, J., Kashnitsky, I., 2020. tricolore: A Flexible Color Scale for Ternary Compositions. R package version 1.2.2 [WWW Document]. URL https://cran.r-project.org/package=tricolore

Schulte, L.A., Mladenoff, D.J., Burrows, S.N., Sickley, T.A., Nordheim, E. V., 2005. Spatial controls of pre-Euro-American wind and fire disturbance in northern Wisconsin (USA) forest landscapes. Ecosystems 8, 73-94. https://doi.org/10.1007/s10021-004-0052-8

Silver, W.L., Neff, J., McGroddy, M., Veldkamp, E., Keller, M., Cosme, R., 2000. Effects of soil texture on belowground carbon and nutrient storage in a lowland Amazonian forest ecosystem. Ecosystems 3, 193-209. https://doi.org/10.1007/s100210000019

Soil Classification Working Group, 1998. The Canadian System of Soil Classification, Third edit. ed. Agric. and Agri-Food Can. Publ. 1646 (Revised).

Soil Science Division Staff, 2017. Soil Survey Manual, USDA Handbook 18. Government Printing Office, Washington, D.C.

Sverdrup, H., Warfvinge, P., 1993. Calculating field weathering rates using a mechanistic geochemical model PROFILE. Appl. Geochemistry 8, 273-283. https://doi.org/10.1016/0883-2927(93)90042-F

Telles, E. de C.C., de Camargo, P.B., Martinelli, L.A., Trumbore, S.E., da Costa, E.S., Santos, J., Higuchi, N., Oliveira, R.C., 2003. Influence of soil texture on carbon dynamics and storage potential in tropical forest soils of Amazonia. Global Biogeochem. Cycles 17, n/a-n/a. https://doi.org/10.1029/2002gb001953

van den Boogaart, G.K., 2020. compositions: Compositional Data Analysis. R package version 1.40-4 [WWW Document]. URL https://cran.r-project.org/package=compositions 
726

727

728

729

730

731

732

733

734

735

736

737

738

739

740

741

742

743

744

745

746

747

748

749

750

751

752

Vaysse, K., Lagacherie, P., 2017. Using quantile regression forest to estimate uncertainty of digital soil mapping products. Geoderma 291, 55-64.

https://doi.org/10.1016/j.geoderma.2016.12.017

Verseghy, D.L., 2007. Class-A Canadian land surface scheme for GCMS. I. Soil model. Int. J. Climatol. 11, 111-133. https://doi.org/10.1002/joc.3370110202

Viscarra Rossel, R.A., Behrens, T., Ben-Dor, E., Brown, D.J., Demattê, J.A.M., Shepherd, K.D., Shi, Z., Stenberg, B., Stevens, A., Adamchuk, V., Aïchi, H., Barthès, B.G., Bartholomeus, H.M., Bayer, A.D., Bernoux, M., Böttcher, K., Brodský, L., Du, C.W., Chappell, A., Fouad, Y., Genot, V., Gomez, C., Grunwald, S., Gubler, A., Guerrero, C., Hedley, C.B., Knadel, M., Morrás, H.J.M., Nocita, M., Ramirez-Lopez, L., Roudier, P., Campos, E.M.R., Sanborn, P., Sellitto, V.M., Sudduth, K.A., Rawlins, B.G., Walter, C., Winowiecki, L.A., Hong, S.Y., Ji, W., 2016. A global spectral library to characterize the world's soil. Earth-Science Rev. 155, 198-230. https://doi.org/10.1016/j.earscirev.2016.01.012

Wadoux, A.M.J.C., Minasny, B., McBratney, A.B., 2020. Machine learning for digital soil mapping: Applications, challenges and suggested solutions. Earth-Science Rev. 210, 103359. https://doi.org/10.1016/j.earscirev.2020.103359

Webb, R.S., Rosenzweig, C.E., Levine, E.R., 1993. Specifying land surface characteristics in general circulation models: Soil profile data set and derived water-holding capacities. Global Biogeochem. Cycles 7, 97-108. https://doi.org/10.1029/92GB01822

Wickham, H., 2016. ggplot2: Elegant Graphics for Data Analysis. Springer-Verlag, New York.

Wickham, H., François, R., Henry, L., Müller, K., 2019. dplyr: A Grammar of Data Manipulation. R package version 0.8.3 [WWW Document]. URL https://cran.rproject.org/package $=$ dplyr

Wiklander, L., 1975. The role of neutral salts in the ion exchange between acid precipitation and soil. Geoderma 14, 93-105. https://doi.org/10.1016/0016-7061(75)90068-3

Wilke, C.O., 2019. cowplot: Streamlined Plot Theme and Plot Annotations for "ggplot2". R package version 1.0.0 [WWW Document]. URL https://cran.r-project.org/package=cowplot 
753 Williams, R.J., Duff, G.A., Bowman, D.M.J.S., Cook, G.D., 1996. Variation in the composition and structure of tropical savannas as a function of rainfall and soil texture along a largescale climatic gradient in the Northern Territory, Australia. J. Biogeogr. 23, 747-756. https://doi.org/10.1111/j.1365-2699.1996.tb00036.x

757 Willmott, C.J., Matsuura, K., 2005. Advantages of the mean absolute error (MAE) over the root 758 mean square error (RMSE) in assessing average model performance. Clim. Res. 30, 79-82. https://doi.org/10.3354/cr030079

760 Wright, M.N., Ziegler, A., 2017. Ranger: A fast implementation of random forests for high dimensional data in C++ and R. J. Stat. Softw. 77. https://doi.org/10.18637/jss.v077.i01

762 Yin, X., Arp, P.A., 1993. Predicting forest soil temperatures from monthly air temperature and 763 precipitation records. Can. J. For. Res. 23, 2521-2536. https://doi.org/10.1139/x93-313 
Figure 1

Forest subzones and soil provinces in Quebec, Canada.

Maps were produced with QGIS software, version 3.4 (QGIS.org, 2020). Basemap credit:

@ 2021 TerraMetrics, @2021 Google, Esri, HERE, Garmin, @ OpenStreetMap contributors, and the GIS User Community. 

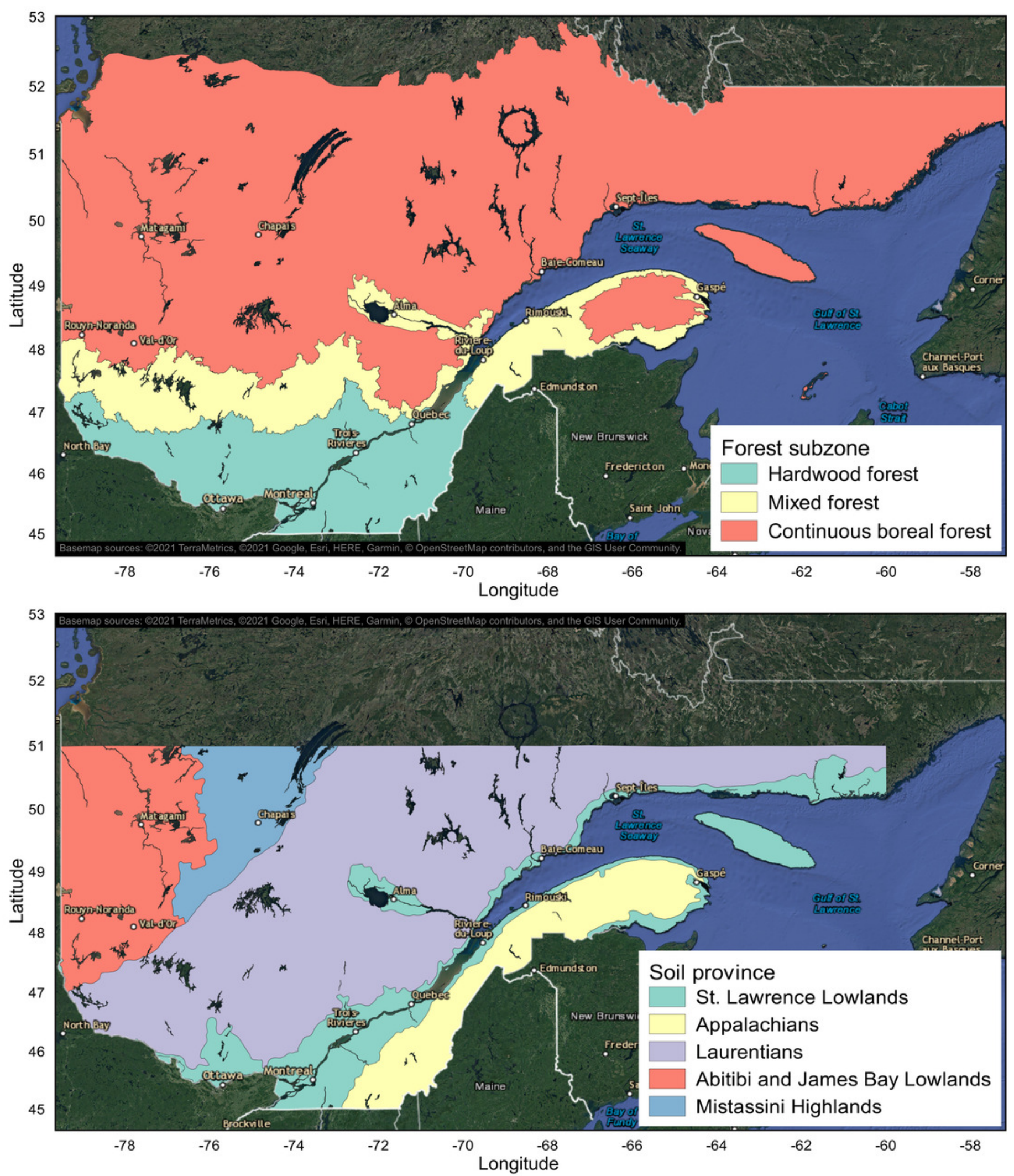


\section{Figure 2}

Spatial distribution of mineral soil texture analysis $(n=29,570)$ from 3 provincial forest inventory programs in Quebec, Canada.

PSP: permanent sampling plots; EOP: ecological observation plots; SIP: site index plots. The map was produced with QGIS software, version 3.4 (QGIS.org, 2020). Basemap credit: ( 2021 TerraMetrics, (C2021 Google, Esri, HERE, Garmin, (c) OpenStreetMap contributors, and the GIS User Community.

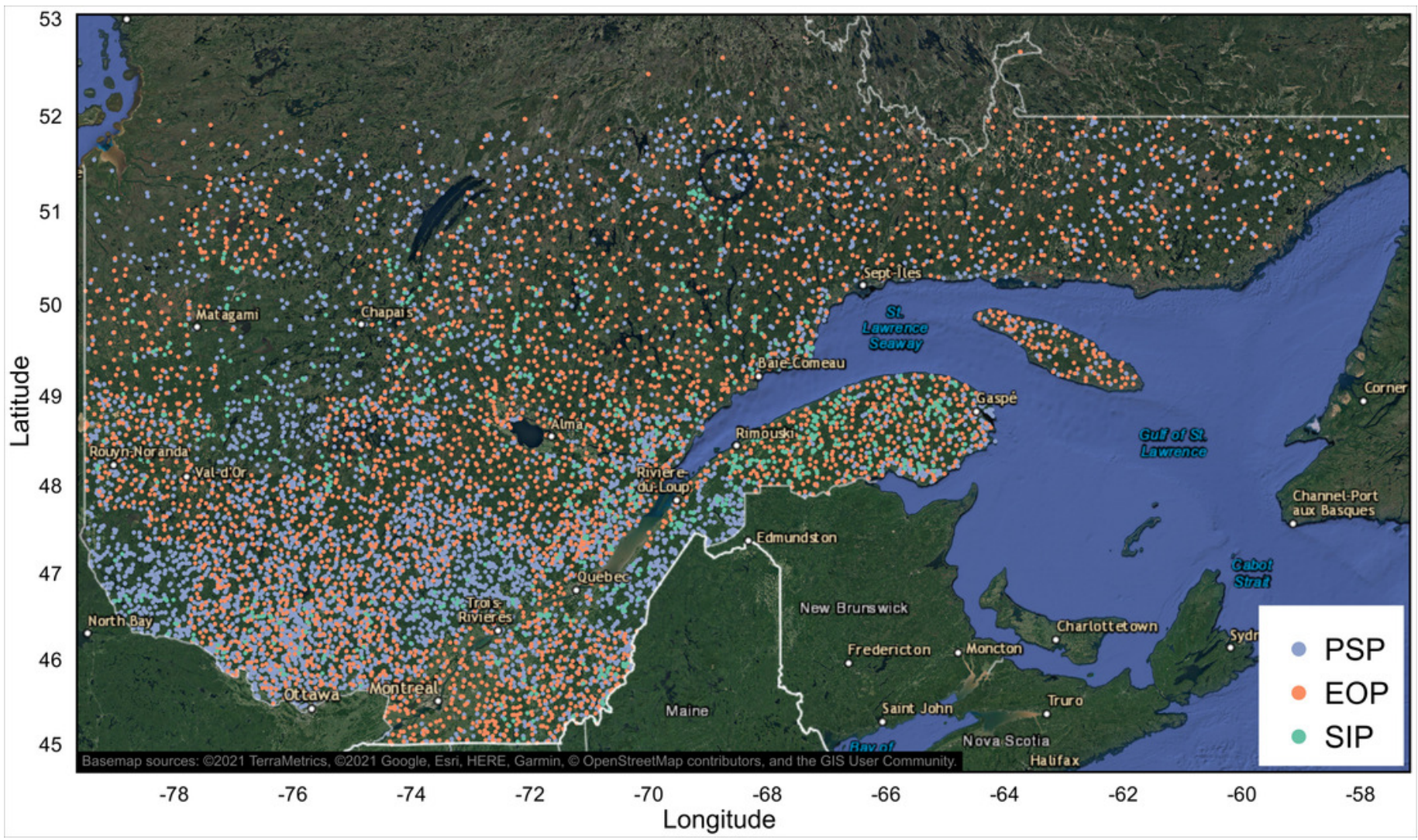




\section{Figure 3}

Observed vs. predicted values of the V1 and V2 orthogonal components of each soil sample's particle size composition (sand, silt and clay fractions).

The strait blue line corresponds to the linear regression between observed and predicted values, and dotted lines represent the 1:1 line. The 0 values of observed V1 that are aligned horizontally in the top graph correspond to observations with an identical composition of sand and silt or to soils composed entirely of sand (100\%), while those of observed V2 in the bottom graph correspond to soils characterized by $0 \%$ clay. The lower rows of horizontally aligned V1 values (top graph) correspond to integer sand values of sandy soils ( $>90 \%)$. 

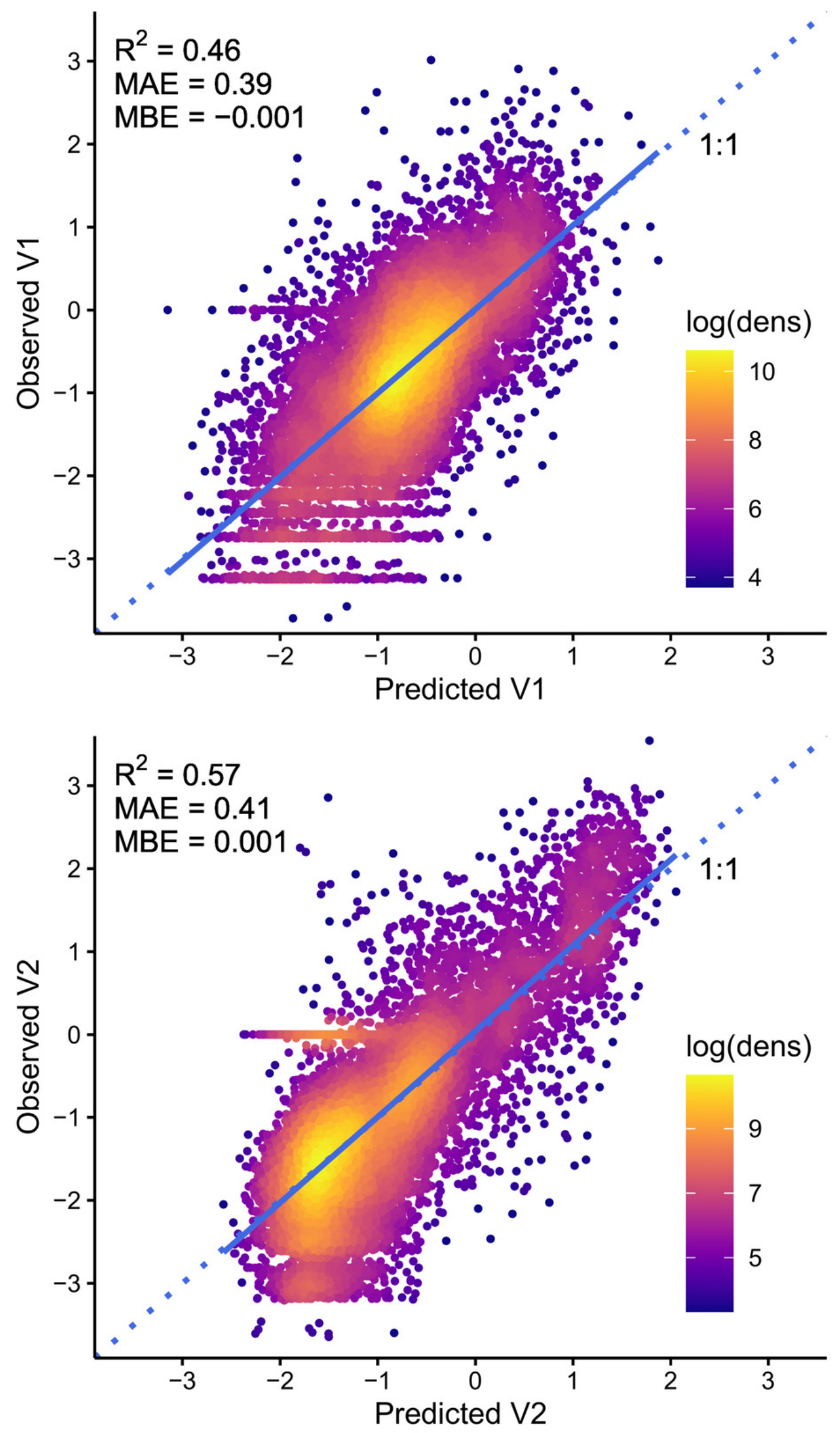
Figure 4

Observed soil texture composition (sand, silt and clay fractions) vs. predicted values, back-transformed from ILR-transform (V1 and V2) predictions.

The strait blue line corresponds to the linear regression between observed and predicted values, and dotted lines represent the 1:1 line. 

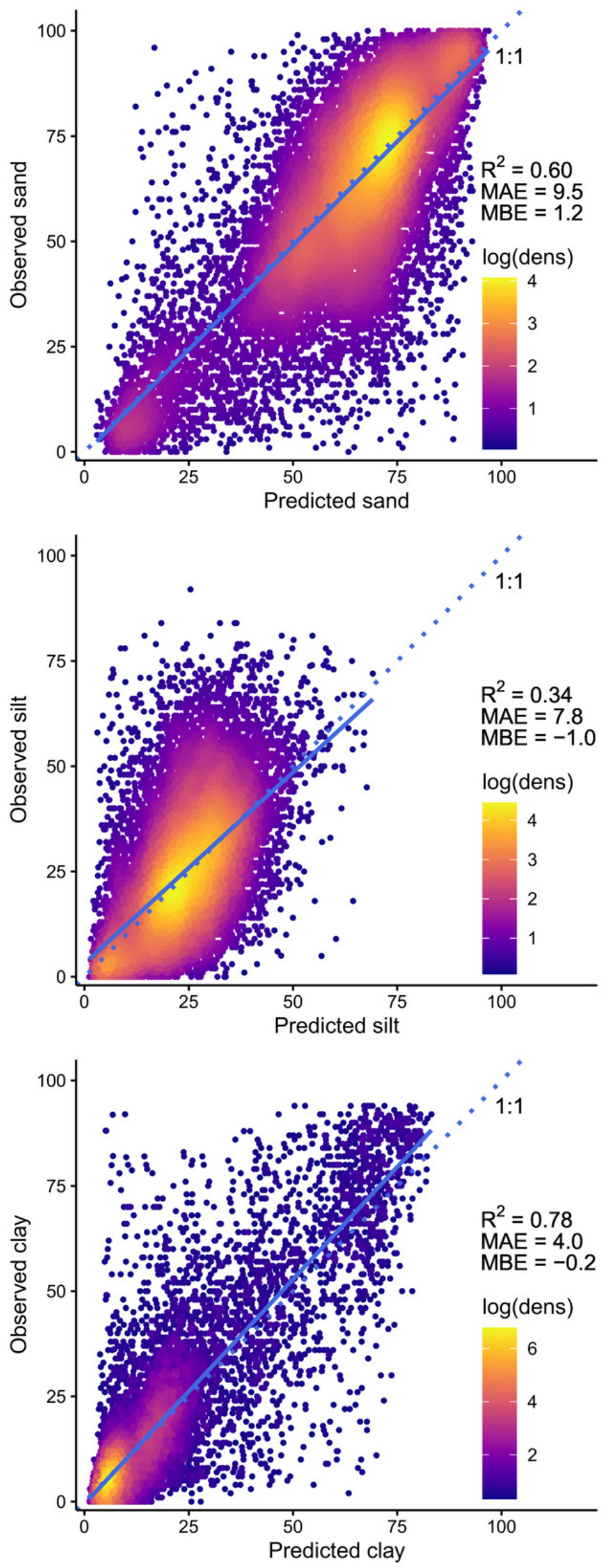
Figure 5

\author{
Relative measures of variable importance in the selected models of the 2 orthogonal \\ components (V1: left panel; V2: right panel) of soil texture composition (sand, silt and \\ clay fractions).
}

Dot color indicates variable category. Only the 50 most important variables are shown. See Tablel for covariate definitions.

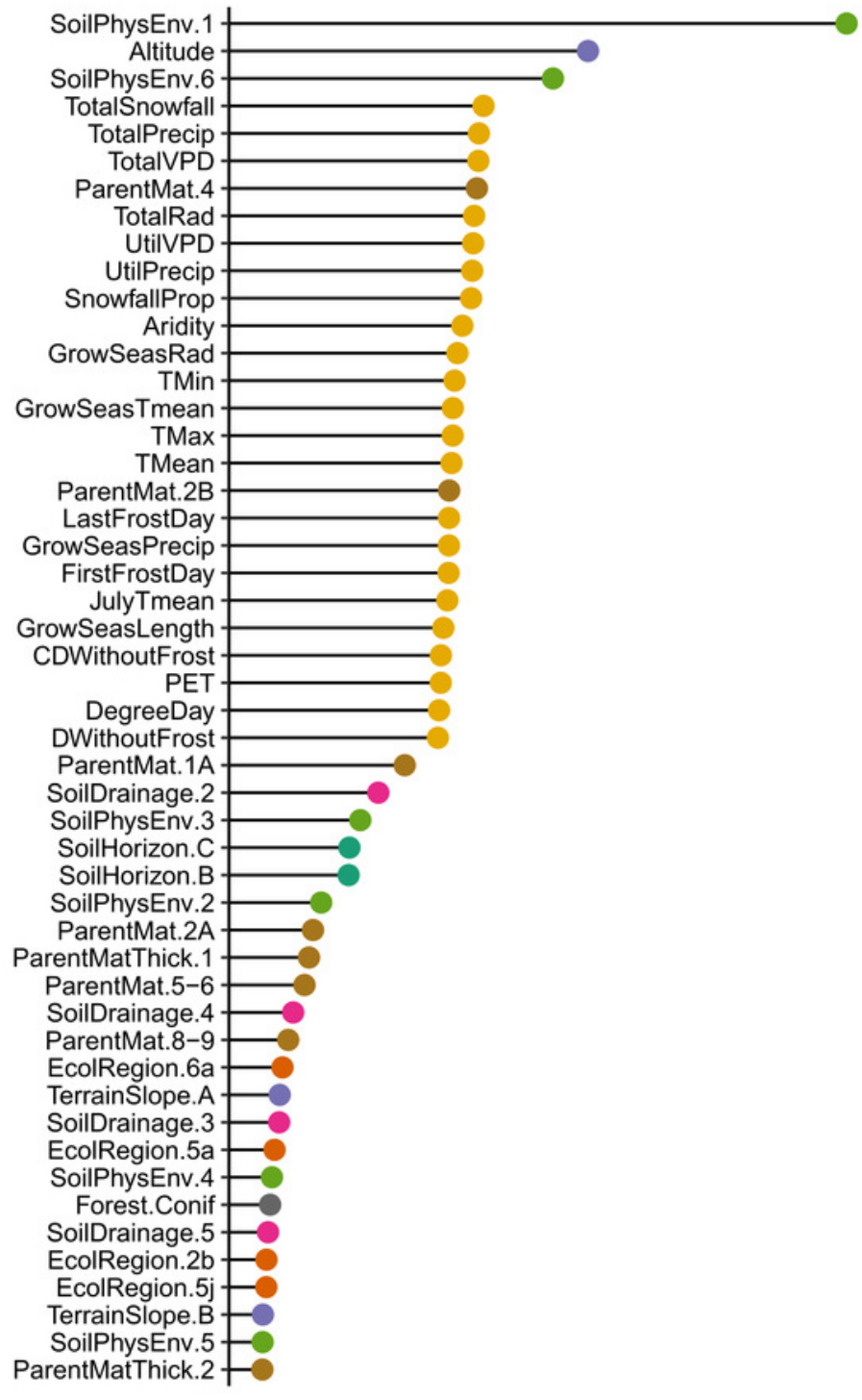

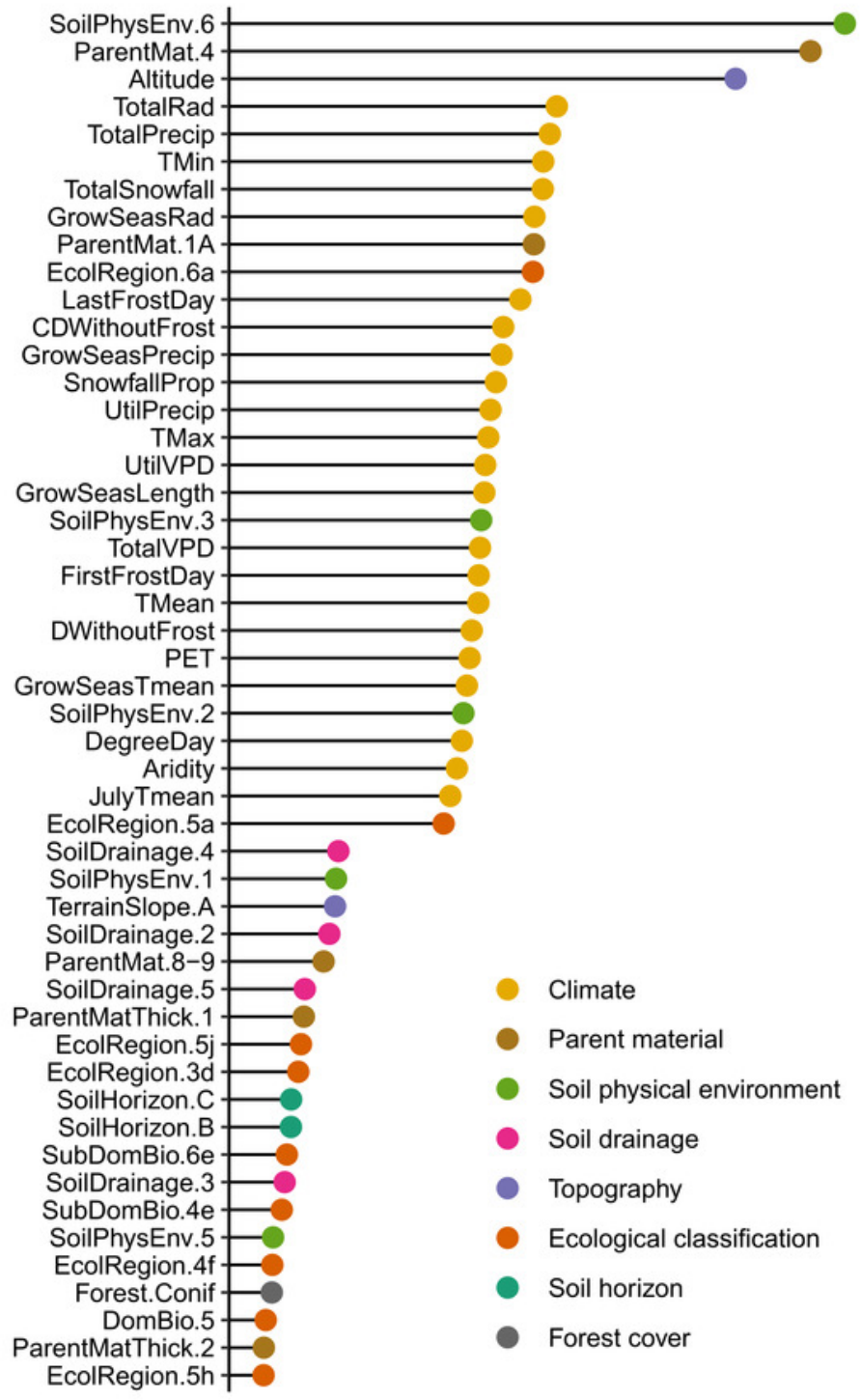




\section{Figure 6}

Variograms illustrating the spatial dependence structure of the V1 and V2 orthogonal components of observed soil particle size composition of the B horizon and of the model's residuals.

The lower dotted horizontal lines represent nuggets (y-axis intercept-related amount of shortrange variability in the data) and the upper lines represent the sills (total variance at which the model first flattens out). Vertical dotted lines represent the range (distance beyond which data are no longer spatially correlated). NSR: nugget-to-sill ratio. 

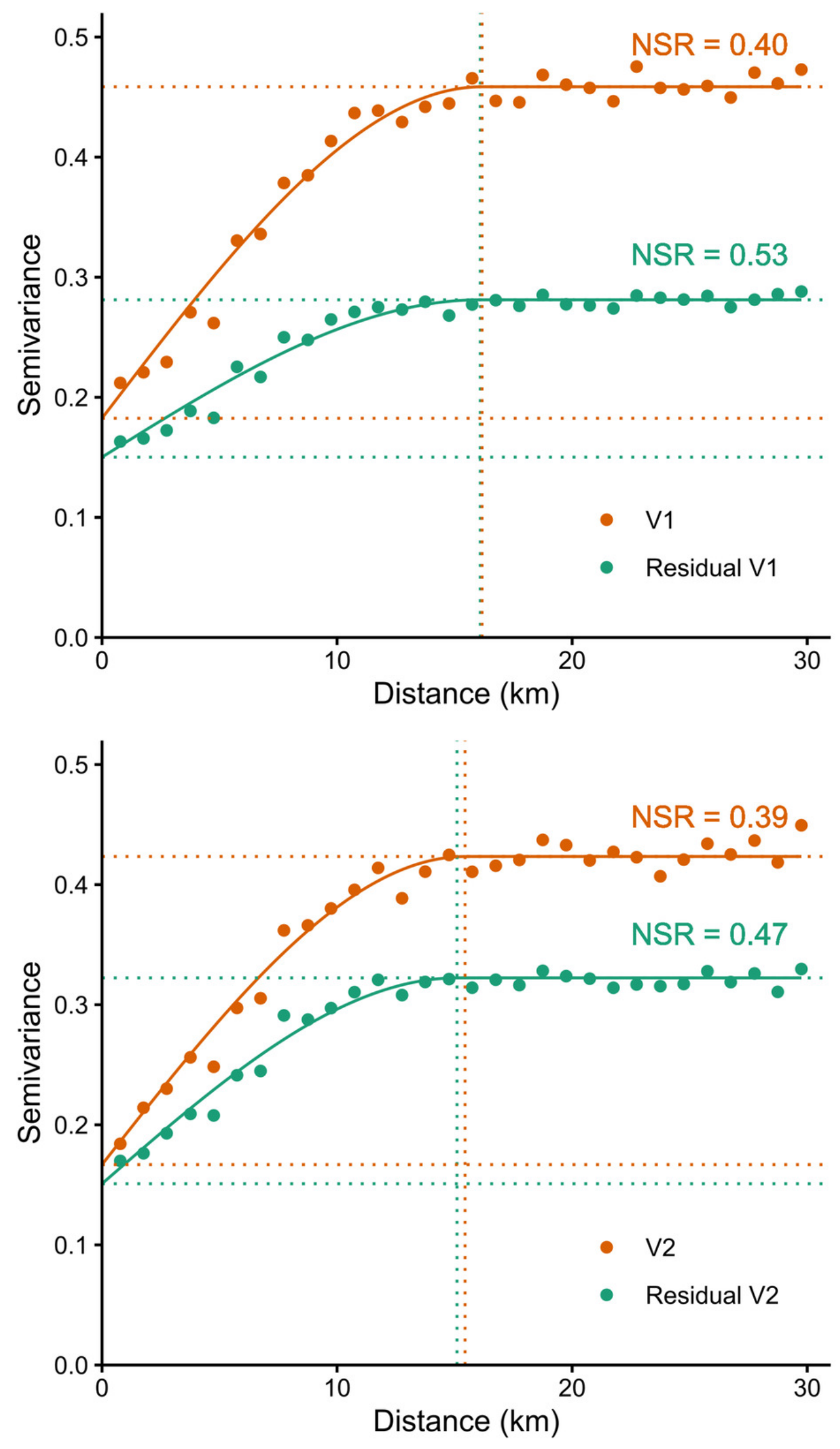


\section{Figure 7}

Gridded map (15 second resolution) of soil texture composition (diagnostic B horizon) in ecoforest polygons of the managed forest of the province of Quebec, Canada.

Only productive forest land characterized by mineral soils was mapped. Agricultural and unproductive forest land, organic soils, anthropogenic infrastructures, and water areas were excluded. Hillshade effect was added based on a $1 \mathrm{~km}$ resolution digital elevation model. The map was produced with QGIS software, version 3.4 (QGIS.org, 2020). Basemap credit: (C2021 TerraMetrics, (c)2021 Google.

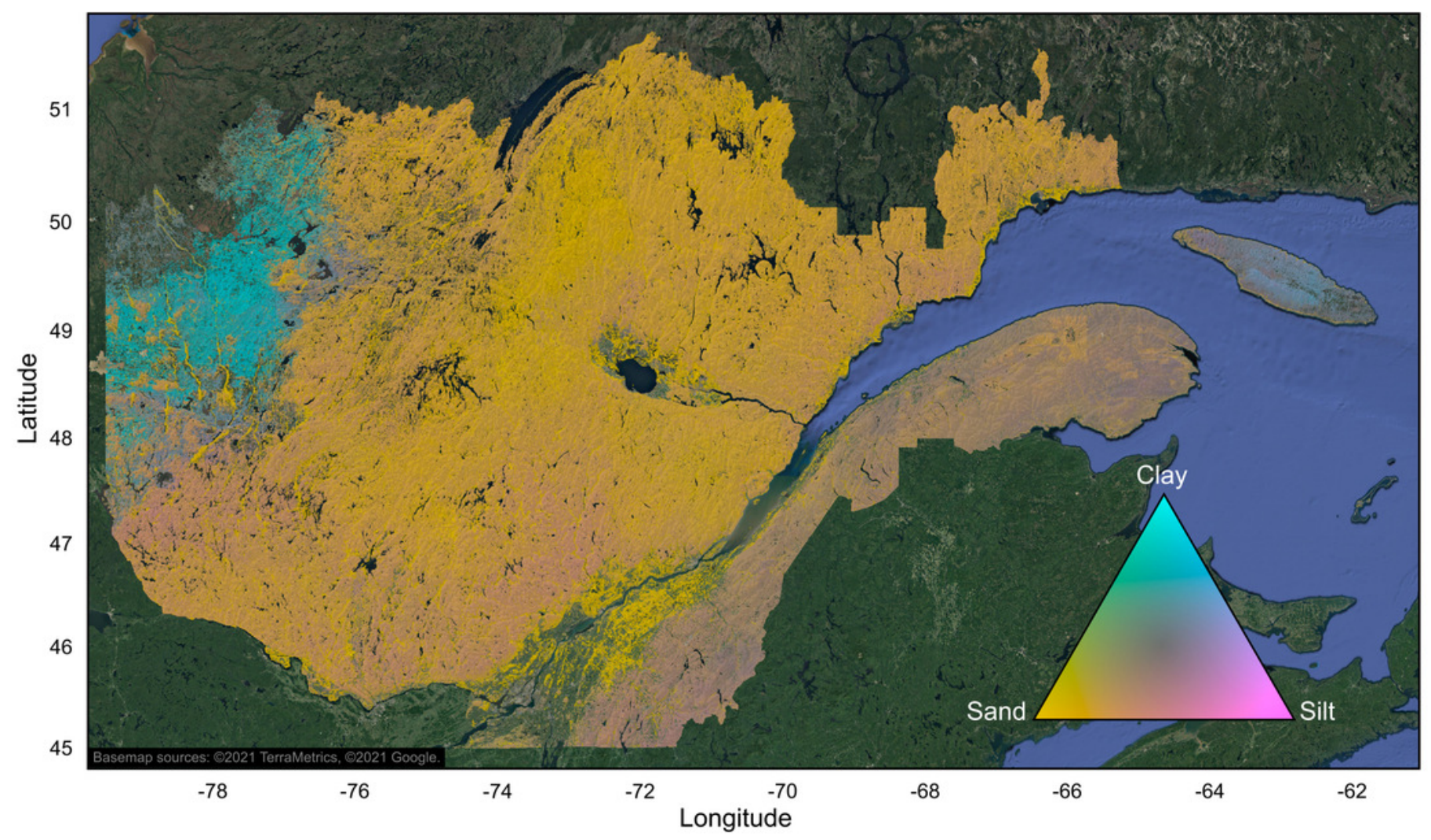




\section{Figure 8}

Maps of soil texture composition at two zoom levels, for a region at the southern edge of the Abitibi and James Bay Lowlands soil province.

Only productive forest land characterized by mineral soils was mapped. Agricultural and unproductive forest land, organic soils, anthropogenic infrastructures, and water areas were excluded. Maps were produced with QGIS software, version 3.4 (QGIS.org, 2020). Basemap credit: @2021 TerraMetrics, @2021 Google. 

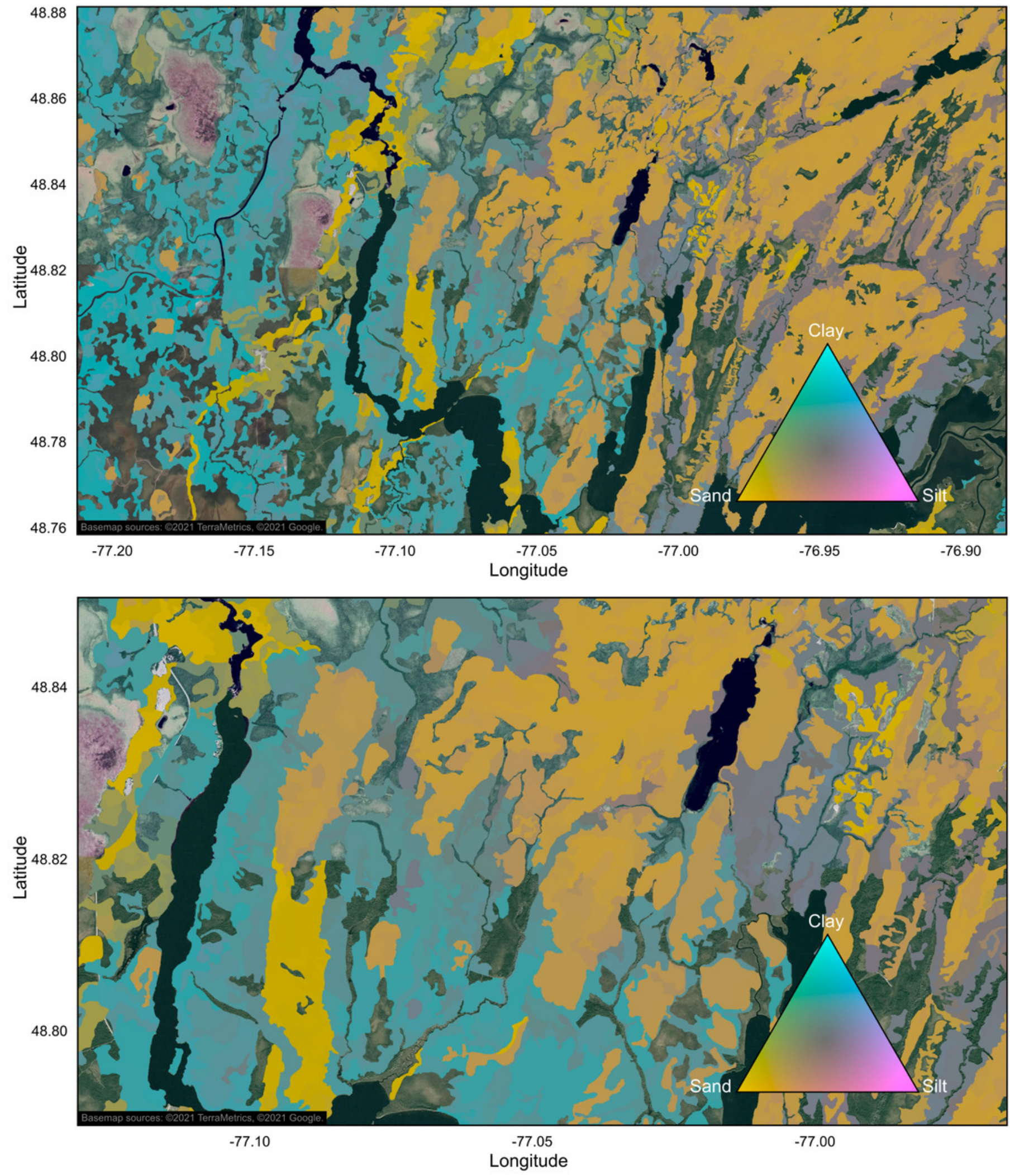


\section{Figure 9}

Gridded map (15 second resolution) of the $95 \%$ prediction intervals of the V1 and V2 orthogonal components of soil texture composition (B horizon) in ecoforest polygons of the province of Quebec.

Only productive forest land characterized by mineral soils was mapped. Agricultural and unproductive forest land, organic soils, anthropogenic infrastructures, and water areas were excluded. Maps were produced with QGIS software, version 3.4 (QGIS.org, 2020). Basemap credit: @2021 TerraMetrics, @2021 Google. 

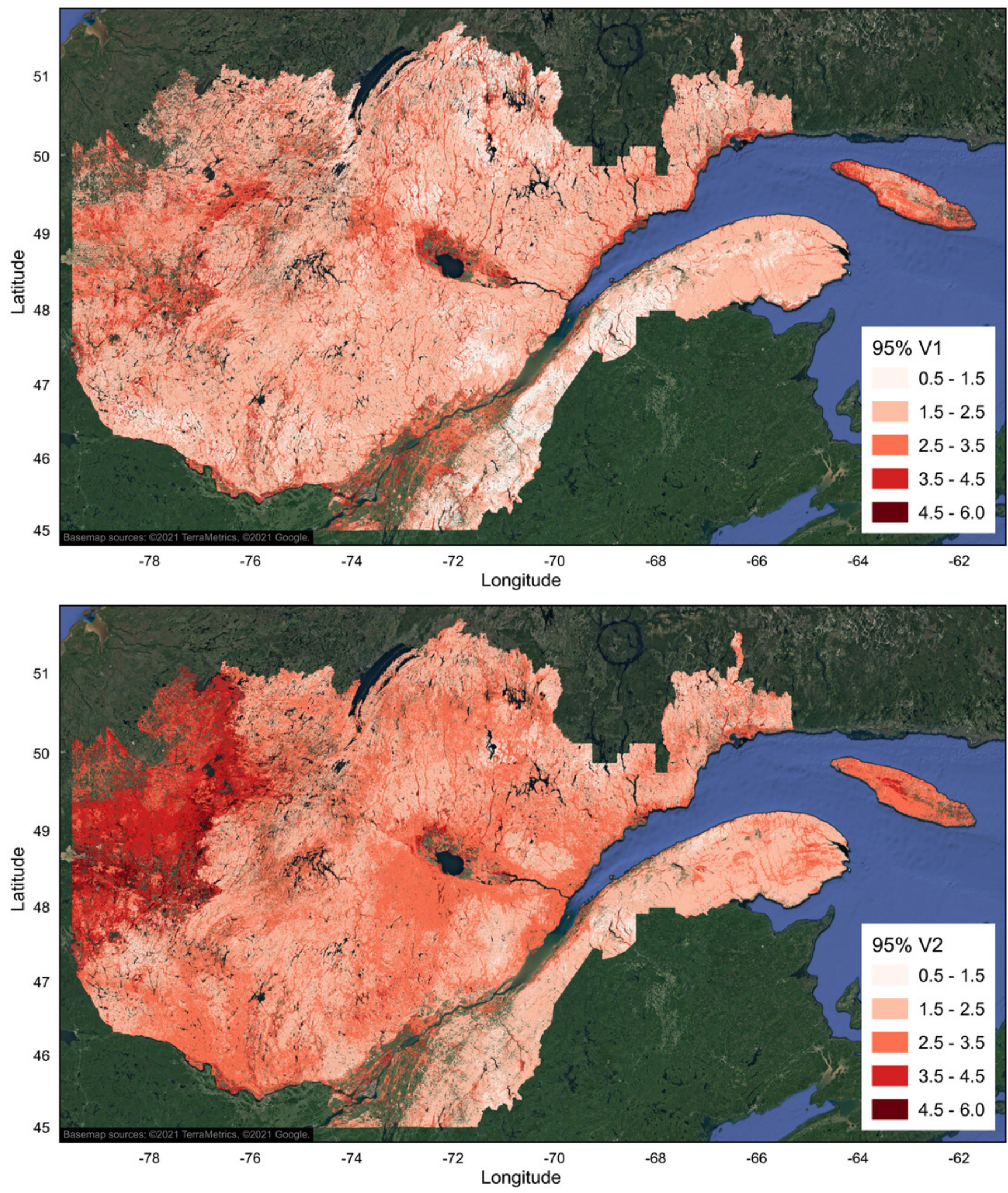


\section{Table $\mathbf{1}$ (on next page)}

List of environmental covariates used for soil texture modelling. 


\section{Table 1. List of environmental covariates used for soil texture modelling.}

\begin{tabular}{|c|c|c|}
\hline Category & \multicolumn{2}{|c|}{ Covariates } \\
\hline \multicolumn{3}{|c|}{ Climate, annual averages (1981-2010) } \\
\hline & 1 & Mean daily minimum temperature $\left({ }^{\circ} \mathrm{C}\right)$. \\
\hline & 2 & Mean daily maximum temperature $\left({ }^{\circ} \mathrm{C}\right)$. \\
\hline & 3 & Mean daily mean temperature $\left({ }^{\circ} \mathrm{C}\right)$ \\
\hline & 4 & Mean daily mean temperature during growing season ${ }^{1}\left({ }^{\circ} \mathrm{C}\right)$. \\
\hline & 5 & Mean daily mean temperature in July $\left({ }^{\circ} \mathrm{C}\right)$. \\
\hline & 6 & Total number of days without frost (days). \\
\hline & 7 & Longest period of consecutive days without frost (days). \\
\hline & 8 & Growing season length $^{1}$ (days). \\
\hline & 9 & Growing degree-day summation over $5^{\circ} \mathrm{C}\left({ }^{\circ} \mathrm{C}\right)$. \\
\hline & 10 & Last frost day at spring (Julian day). \\
\hline & 11 & First frost day at falls (Julian day). \\
\hline & 12 & Aridity $(\mathrm{mm})^{2}$ \\
\hline & 13 & Total precipitation $(\mathrm{mm})$. \\
\hline & 14 & Total precipitation in June, July and August (mm). \\
\hline & 15 & Total precipitation during growing season $(\mathrm{mm})$. \\
\hline & 16 & Total vapor pressure deficit $(\mathrm{hPa})$ \\
\hline & 17 & Total vapor pressure deficit in June, July and August (mm). \\
\hline & 18 & Total Thornthwaite potential evapotranspiration (PET, mm). \\
\hline & 19 & Snowfall proportion (\%). \\
\hline & 20 & Total snowfall ( $\mathrm{mm}$ of water). \\
\hline & 21 & Total radiation $\left(\mathrm{MJ} / \mathrm{m}^{2}\right)$ \\
\hline & 22 & Total radiation during growing season ${ }^{1}\left(\mathrm{MJ} / \mathrm{m}^{2}\right)$. \\
\hline \multicolumn{3}{|c|}{ Soil characteristics } \\
\hline & 1 & Soil horizon (diagnostic B or C). \\
\hline & 2 & $\begin{array}{l}\text { Soil parent material: glacial without particular morphology (1A); glacial characterized by its morphology (1B); } \\
\text { juxtaglacial (2A); proglacial (2B); fluvial (3); lacustrine (4); marine and littoral (5-6); thick organic (7E); thin organic } \\
\text { (7T), slope and in situ weathered (8); eolian (9); bedrock (R, } \geq 50 \% \text { of exposed bedrock). }\end{array}$ \\
\hline & 3 & $\begin{array}{l}\text { Thickness of the soil parent material: thick }(1:>1 \mathrm{~m}) \text {; medium }(2: \geq 50 \mathrm{~cm} \text { to } 1 \mathrm{~m}) \text {; thin }(3: \geq 25 \mathrm{~cm} \text { to } 50 \mathrm{~cm}) \text {; very thin } \\
(4:<25 \mathrm{~cm}) \text {; thin to very thin }(5:<50 \mathrm{~cm}, \geq 25 \% \text { to }<50 \% \text { of exposed bedrock); very thin or absent }(6: \geq 50 \% \text { of exposed } \\
\text { bedrock). }\end{array}$ \\
\hline & 4 & $\begin{array}{l}\text { Soil drainage: excessively drained (0); somewhat excessively drained (1); well drained (2); moderately well drained (3); } \\
\text { somewhat poorly drained (4); poorly drained (5); very poorly drained (6); complex (16). }\end{array}$ \\
\hline & 5 & $\begin{array}{l}\text { Soil physical environment: based on a combination of synthetic soil texture (fine, medium, coarse) and synthetic soil } \\
\text { moisture regime (subhydric, hydric, mesic, xeric) classes: Very thin }(<25 \mathrm{~cm} \text { ) mineral deposit, variously textured, xeric to } \\
\text { hydric moisture regime or thin to thick mineral deposit, xeric to hydric moisture regime, very stony without matrix (0); } \\
\text { Thin to thick mineral deposit, coarse texture, xeric or mesic moisture regime (1); Thin to thick mineral deposit, medium } \\
\text { texture, mesic moisture regime (2); Thin to thick mineral deposit, fine texture, mesic moisture regime (3); Thin to thick } \\
\text { mineral deposit, coarse texture, subhydric moisture regime (4); Thin to thick mineral deposit, medium texture, subhydric } \\
\text { moisture regime (5); Thin to thick mineral deposit, fine texture, subhydric moisture regime (6); Thin to thick mineral } \\
\text { deposit, hydric moisture regime, umbrotrophic (7); Thin to thick organic or mineral deposit, hydric moisture regime, } \\
\text { minerotrophic (8); Thin to thick organic deposit, hydric moisture regime, umbrotrophic (9). (Organic soils were excluded } \\
\text { from the modelling). }\end{array}$ \\
\hline \multicolumn{3}{|r|}{ (1) } \\
\hline & 1 & Bioclimatic domains $(n=7)$. \\
\hline & 2 & Bioclimatic subdomains $(\mathrm{n}=12)$. \\
\hline & 3 & Ecological regions $(n=46)$ \\
\hline \multicolumn{3}{|c|}{ Relief and topography } \\
\hline & 1 & Altitude (m). \\
\hline & 2 & Slope: $0 \%$ to $3 \%(\mathrm{~A}) ; 4 \%$ to $8 \%(\mathrm{~B}) ; 9 \%$ to $15 \%(\mathrm{C}) ; 16 \%$ to $30 \%(\mathrm{D}) ; 31 \%$ to $40 \%(\mathrm{E}) ; \geq 41 \%(\mathrm{~F})$; summit (S). \\
\hline
\end{tabular}

Vegetation

Forest cover: deciduous (relative basal area of coniferous species $<25 \%$ ); mixed (relative basal area of coniferous species between $25 \%$ and $74 \%$ ); coniferous (relative basal area of coniferous species $>75 \%$ ); Non-forested (cover density $<25 \%$ ).

$2{ }^{1}$ Growing season length is defined as the period (number of days) between the last 3 consecutive days with frost (daily 3 minimum temperature $<0{ }^{\circ} \mathrm{C}$ ) in the spring and the first 3 consecutive days with frost in the fall.

42 Aridity is the accumulation of monthly water deficit (difference between monthly Thornthwaite potential 5 evapotranspiration and monthly precipitation, zero if negative). 